OPEN ACCESS

Edited by:

Sophie Hillion,

INSERM U1227 Lymphocytes B et Autoimmunite (LBAl), France

Reviewed by: Sébastien Lacroix-Desmazes, Institut National de la Santé et de la

Recherche Médicale (INSERM),

France

Carlo Chizzolini,

Université de Genève, Switzerland

*Correspondence: Philippe Mondon mondonp@lfb.fr

Specialty section: This article was submitted to

Autoimmune and

Autoinflammatory Disorders,

a section of the journal

Frontiers in Immunology

Received: 21 June 2021 Accepted: 09 August 2021 Published: 26 August 2021

Citation:

Monnet $C$, Jacque $E$, de Romeuf $C$ Fontayne A, Abache T, Fournier N,

Dupont G, Derache D, Engrand $A$,

Bauduin A, Terrier A, Seifert $A$

Beghin C, Longue A, Masiello N,

Danino L, Nogre M, Raia A,

Dhainaut F, Fauconnier L, Togbe $D$

Reitinger C, Nimmerjahn F, Stevens W,

Chtourou $S$ and Mondon P (2021) The

Dual Targeting of FCRn and FCyRs

via Monomeric FC Fragments Results in Strong Inhibition of IgG-Dependent

Autoimmune Pathologies.

Front. Immunol. 12:728322.

doi: 10.3389/fimmu.2021.728322

\section{The Dual Targeting of FcRn and FcyRs via Monomeric Fc Fragments Results in Strong Inhibition of IgG- Dependent Autoimmune Pathologies}

Céline Monnet ${ }^{1}$, Emilie Jacque ${ }^{1}$, Christophe de Romeuf ${ }^{1}$, Alexandre Fontayne ${ }^{1}$, Toufik Abache ${ }^{1}$, Nathalie Fournier ${ }^{1}$, Gilles Dupont ${ }^{1}$, Delphine Derache ${ }^{1}$, Anais Engrand ${ }^{1}$, Aurélie Bauduin ${ }^{1}$, Aurélie Terrier ${ }^{1}$, Alexander Seifert ${ }^{1}$, Cécile Beghin ${ }^{1}$, Alain Longue ${ }^{1}$, Nicholas Masiello ${ }^{1}$, Laetitia Danino ${ }^{1}$, Michel Nogre ${ }^{1}$, Anais Raia ${ }^{1}$, Frederic Dhainaut ${ }^{1}$, Louis Fauconnier ${ }^{2}$, Dieudonnée Togbe ${ }^{2}$, Carmen Reitinger ${ }^{3}$, Falk Nimmerjahn ${ }^{3}$, Wil Stevens ${ }^{1}$, Sami Chtourou ${ }^{1}$ and Philippe Mondon ${ }^{1 *}$

\section{${ }^{1}$ LFB Biotechnologies, Innovation Department, Les Ulis, France, ${ }^{2}$ Artimmune, Orléans, France, ${ }^{3}$ Division of Genetics, Department of Biology, Friedrich-Alexander University Erlangen-Nürnberg, Erlangen, Germany}

Novel molecules that directly target the neonatal Fc receptor (FcRn) and/or Fc gamma receptors (FcyRs) are emerging as promising treatments for immunoglobulin $G$ (lgG)dependent autoimmune pathologies. Mutated $\mathrm{F}_{\mathrm{C}}$ regions and monoclonal antibodies that target FCRn are currently in clinical development and hold promise for reducing the levels of circulating lgG. Additionally, engineered structures containing multimeric Fc regions allow the dual targeting of FcRn and FcyRs; however, their tolerance needs to first be validated in phase I clinical studies. Here, for the first time, we have developed a modified monomeric recombinant Fc optimized for binding to all FcRns and FcyRs without the drawback of possible tolerance associated with FcyR cross-linking. A rational approach using Fc engineering allowed the selection of LFBD192, an Fc with a combination of six mutations that exhibits improved binding to human FcRn and FcyR as well as mouse FcRn and FcyRIV. The potency of LFBD192 was compared with that of intravenous immunoglobulin (IVIg), an FCRn blocker (FC-MST-HN), and a trimeric FC that blocks FcRn and/or immune complex-mediated cell activation through FcyR without triggering an immune reaction in several in vitro tests and validated in three mouse models of autoimmune disease.

Keywords: FcRn, Fc fragment, Fc engineering, autoantibodies, autoimmune disease, immune complex (IC), Fc gamma receptor $(\mathrm{Fc} \gamma \mathrm{R})$

\section{INTRODUCTION}

Immunoglobulin $\mathrm{G}$ (IgG)-targeting autoantigens play a central role in several autoimmune disorders, including immune thrombocytopenia (ITP), myasthenia gravis, multiple sclerosis, pemphigus vulgaris, and systemic lupus erythematosus. Strategies such as plasmapheresis, highdose intravenous immunoglobulin (hdIVIg), and B-cell-depleting therapies (e.g., rituximab) that 
decrease the levels of circulating antibodies, including autoantibodies, are effective in treating some autoimmune diseases (1). The neonatal Fc receptor FcRn functions mainly in the recovery and recycling of IgG, providing it with a long plasma half-life (approximately 3 weeks) in humans. Several molecules under development, such as modified Fcs and monoclonal antibodies (mAbs), target FcRn to increase endogenous IgG clearance, including that of pathogenic IgG, to levels similar to those seen with plasmapheresis. A modified IgG1-Fc fragment (efgartigimod) encompassing the ABDEG mutations (M252Y/S254T/T256E/H433K/N434F) (2) has shown efficacy in reducing IgG levels in humans (3) and promoted long-lasting disease improvement (4). Several mAbs that block FcRn have also been shown to lower plasma IgG levels in humans $(5,6)$, with $53.3 \%$ of ITP patients showing improvement in platelet counts in a phase 2 study (7). However, currently available FcRn-targeting molecules are likely to be limited to autoimmune diseases in which pathogenic IgGs have a clear correlation with disease activity and severity (8). It is doubtful whether targeting only one receptor subtype will produce sufficiently broad immunomodulatory effects against multifactorial autoimmune diseases (9).

Autoantibodies comprising immune complexes (ICs) induce the cross-linking of activating Fc $\gamma$ Rs [Fc $\gamma R I$ (CD64), Fc $\gamma$ RIIIa (CD16a), and FcyRIIa (CD32a)] through their Fc region, which initiates the phosphorylation of immunoreceptor tyrosine-based activation motifs (ITAMs), ultimately leading to the activation of cellular responses such as antibody-dependent cell-mediated cytotoxicity (ADCC) and antibody-dependent cellular phagocytosis (ADCP). The first clinical proof of concept using an Fc fragment to block Fc receptors was reported in 1993 for ITP (10) and Kawasaki disease (11). Additionally, in April 2018, the United States Food and Drug Administration approved the use of fostamatinib (Tavalisse), an oral spleen tyrosine kinase (SYK) inhibitor that blocks the activation of pathways downstream of Fc $\gamma R(12,13)$, as a second-line treatment for patients with chronic ITP. Anti-RhD IgG IC formation with red blood cells also displays efficiency in treating $\mathrm{RhD}$-positive ITP patients through competing with pathogenic ICs. Fc $\gamma \mathrm{R}$ polymorphisms have also been associated with autoimmune diseases (14). Furthermore, blocking activating FcyRs and modulating their expression represent key mechanisms underlying the ability of IVIg to treat several autoimmune diseases (15).

The Fc $\gamma$ RIIIa involvement was clearly shown in humans for the first time in 1986 with the anti-FcyRIIIa 3G8 mAb, which raised the platelet level in $50 \%$ of immune thrombocytopenic purpura patients refractory to other treatments $(16,17)$; however, the $3 \mathrm{G} 8 \mathrm{mAb}$ was found to be toxic. Although this effect was originally explained by its murine origin, a humanized version with deglycosylated Fc was unfortunately also toxic due to the avidity of the mAb leading to FcyRIIIa cross-linking (1820). Research is now focused on the development of monovalent Fab fragments or short-chain variable fragments ( $\mathrm{scFv}$ ) fused to albumin. scFv-HAS anti-FcyRIIIa murine version and recently a monovalent anti-Fc $\gamma$ RIII diabody (3G8 Fab paired with an irrelevant Fab) have demonstrated that previous anti- Fc $\gamma$ RIIIa antibodies toxicity may be overcome by monovalent blockade $(20,21)$. In addition, Norris et al. $(20,21)$ in vitro results indicated the involvement of both Fc $\gamma \mathrm{RI}$ and Fc $\gamma$ RIII but not Fc $\gamma$ RIIa in the platelet phagocytosis.

IVIg is considered to be an effective treatment for an increasing number of autoimmune diseases. The major mechanism of action of IVIg seems to be related to its $F\left(a b^{\prime}\right) 2$ and $\mathrm{Fc}$ fragments and in particular the dual effect of its $\mathrm{Fc}$ region that both blocks activating FcyRs and saturates FcRn $(15,22)$.

$\mathrm{FcRn}$ and $\mathrm{Fc} \gamma \mathrm{Rs}$ are currently the targets of emerging molecules that display a dual mechanism of action. Recently, the recombinant multimeric Fc design allowed a higher avidity and an increased binding to FcRn and all FcyRs. Multimeric Fc (stradomers) (23), hexameric IgG1-Fc (24), and trimeric Fc (25) were successfully used to block effector pathways in IC-mediated diseases such as ITP and collagen antibody-induced arthritis (CAIA) in mice. The possible drawback of these Fc multimers is the possibility of $\mathrm{Fc} \gamma \mathrm{R}$ cross-linking, which leads to inflammation. Ortiz et al. (25) demonstrated that constructs containing five or more Fc domains induced Fc $\gamma \mathrm{R}$ internalization and elicited ITAM signaling. The safety assessments of multimeric Fc molecules are currently in phase I clinical trials.

Using random mutagenesis and phage display selection, we have previously identified several Fc variants of human IgG1 that are optimized for binding to human FcRn. Based on our random mutagenesis approach, we selected key Fc mutations that were unpredictable by rational design and with synergistic effects in modulating the binding not only to FcRn but also other FcyRs $(26,27)$. Furthermore, the same approach consisting of two rounds of random mutagenesis and selection by phage display relating to Fc $\gamma$ RIIIa and C1q has allowed the identification of new key mutations that modulate binding to FcyRIIIa, FcyRIIa, and C1q (unpublished data). Here, we describe the design of a new Fc variant (LFBD192), with six mutations, that displays an improved capacity for binding to $\mathrm{Fc}$ receptors ( $\mathrm{FcRn}$ and $\mathrm{Fc} \gamma \mathrm{Rs}$ ). This $\mathrm{Fc}$ variant was designed using the best variants obtained after random mutagenesis/phage display selection on FcrRIIIa, with the addition of a key mutation that increases its capacity for binding to FcRn. The ability of LFBD192 to block FcRn and IC-mediated cell activation through FcyRs without triggering an immune reaction was compared with that of IVIg, and FcRn blocker (FcMST-HN), and a trimeric Fc in several in vitro tests. The optimized binding ability of LFBD192 was further validated against the mouse Fc receptors FcRn at $\mathrm{pH} 6.0$ and Fc $\gamma \mathrm{RIV}$ at $\mathrm{pH}$ 7.4. Finally, the efficacy of LFBD192 in vivo was assessed in three mouse models of autoimmune disease and compared to that of IVIg, a molecule that is widely used to treat IC-driven inflammatory diseases.

\section{MATERIALS AND METHODS}

\section{Construct Production and Purification}

Fc-MST-HN and Fc-trimer coding sequences were synthesized according to information available from WO 2016/142782 and WO 2015/168643, respectively. DNA encoding rFc-WT, rFc-C6A74, rFc-T5A-74, and $\mathrm{rFc}-\mathrm{A} 3 \mathrm{~A}-184 \mathrm{~A}$ was prepared from previously 
generated constructs using standard PCR procedures (28). The DNA encoding the eight new variants was prepared by overlap extension PCR using primers containing point mutations, with DNA encoding rFc-C6A-74, rFc-T5A-74, or rFc-A3A-184A serving as a template. The PCR products and synthetic gene assemblies were inserted between the NheI and XhoI restriction sites of the OptiHEK vector, a pCEP4 (Invitrogen) derivate. The expression constructs were used to transiently synthesize each molecule in HEK293 cells or FreeStyle 293-F cells (Thermo Fisher Scientific), or expi293 cells (for the Fc-trimer) (Thermo Fisher Scientific) over 6-7 days. Supernatants were subsequently harvested, clarified by centrifugation at $3,000 \times g$ for $30 \mathrm{~min}$, and sterile filtered before purification by one-step affinity chromatography using protein A Sepharose 4FF (GE Healthcare, Chicago, IL, USA), elution with 25 $\mathrm{mM}$ sodium citrate $(\mathrm{pH} 3.0)$, and dialysis in phosphate-buffered saline (PBS). For the Fc-trimer, affinity chromatography was followed by cation exchange chromatography on SP Sepharose (GE Healthcare) to increase the trimeric form ratio of low and high molecular weight species.

The LFBD192 coding sequence was prepared as codonoptimized cDNA for expression in $\mathrm{CHO}$ by GeneArt (Thermo Fisher Scientific) and subcloned into the proprietary vector HKgenEFss to improve molecule titer during the bioproduction steps. A stable pool was generated in the Freestyle CHO-S (Gibco, Thermo Fisher Scientific) cell line and used for production in serum-free CD FortiCHO medium containing $8 \mathrm{mM}$ L-glutamine and 4-6 g/L glucose over 10 days in a feedback mode with carbon feed. The supernatant was recovered when cell viability fell below $50 \%$, clarified by depth filtration using a MDOHC filter (Merck), and sterile filtered with a Millipak 200 (Merck) before two-step purification. LFBD192 was affinity-captured with rProtein A matrix (MAbSelect SuRe, GE Healthcare), eluted with glycine buffer (pH 3.0), followed by adjustment to $\mathrm{pH} 5.5$ for HCP flocculation. The filtrated eluate was further purified using a cation exchanger (Capto-S, GE Healthcare). Sodium chloride eluate was concentrated to $20 \mathrm{~g} / \mathrm{L}$, formulated by ultrafiltration (Centramate, PALL), and sterile filtered (Sartopore2, Sartorius). Formulated LFBD192 was stored at $-80^{\circ} \mathrm{C}$. Protein integrity and purity were evaluated by SDS-PAGE, size exclusion chromatography (Superdex 200; GE Healthcare), and dynamic light scattering (Dynapro Nanostar, Wyatt), while endotoxin content was determined by limulus amebocyte lysate (LAL) testing. Protein identity and glycan structure were determined by liquid chromatography-mass spectrometry (LC-MS).

\section{Octet Binding}

Affinities for the human FcRn receptor were determined by BioLayer Interferometry (BLI) using a RED96 OCTET system (PALL ForteBio). A recombinant human FcRn receptor (a FcRn $\alpha$-chain and $\beta 2$-microglobulin heterodimer) produced in baculovirus (GTP, Toulouse, France) was biotinylated using the EZ-link NHS-PEO kit (Pierce). The biotinylated receptor was diluted to $0.7 \mu \mathrm{g} / \mathrm{mL}$ in phosphate buffer $(0.1 \mathrm{M}$ phosphate, 150 $\mathrm{mM} \mathrm{NaCl}, 0.05 \%$ Tween 20, $\mathrm{pH}$ 6.0) and fixed on streptavidin biosensors (PALL ForteBio 18-5019) for 300 s. Samples were tested for association and dissociation kinetics at 200, 100, 50, 25, $12.5,6.25,3.125$, and $0 \mathrm{nM}$ in buffer at $\mathrm{pH} 6.0$ for $60 \mathrm{~s}$ and $30 \mathrm{~s}$, respectively. Samples were released from the receptor using regeneration buffer $(0.1 \mathrm{M}$ phosphate, $150 \mathrm{mM} \mathrm{NaCl}, 0.05 \%$ Tween 20, pH 7.8). For analysis of the results, the biosensors used for the $0 \mathrm{nM}$ measurements served as a reference. The association (Kon) and dissociation (Koff) constants were calculated using a 1/1 model. Recombinant human Fc $\gamma$ RIIIa V/ CD16aV (\#4325-FC, R\&D Systems) containing a C-terminal sixHis tag was diluted to $1 \mu \mathrm{g} / \mathrm{mL}$ in kinetic buffer and fixed on antipenta-His (HIS-1K) biosensors for $300 \mathrm{~s}$. Samples were tested for association and dissociation kinetics at 1,000, 500, 250, 125, 62.5, $31.25,15.625$, and $0 \mathrm{nM}$ in kinetic buffer (\#18-1092, PALL) for $60 \mathrm{~s}$ and $30 \mathrm{~s}$, respectively. Samples were released from the receptor using regeneration buffer (100 $\mathrm{mM}$ glycine, $\mathrm{pH} 1.5)$. For analysis of the results, the biosensors used for the $0 \mathrm{nM}$ measurements served as a reference. The Kon and Koff were calculated using a $1 / 1$ model.

\section{Biacore Kinetic Binding Analysis}

For FcRn and Fc $\gamma R$ kinetics/affinity analysis, a Biacore T200 (GE Healthcare) was used with two different setups, i.e., a sensor chip CAP with a Biotin CAPture Kit (GE Healthcare) was used for FcRn analysis and a sensor chip CM5 with an Anti His Capture Kit (GE Healthcare) was used for Fc $\gamma \mathrm{R}$ analysis, both following supplier recommendations. Phosphate buffer $(20 \mathrm{mM}$ sodium phosphate, $150 \mathrm{mM} \mathrm{NaCl}, 0.05 \%$ Tween 20, $\mathrm{pH}$ 6.0) and Tris buffer (15 mM Tris-HCl, $150 \mathrm{mM} \mathrm{NaCl}, 0.005 \%$ Tween 20, pH 7.4) were used as interaction buffers for FcRn and Fc $\gamma R$ analysis, respectively. For FcRn analysis, biotinylated human or mouse FcRn (Acrobiosystem, Newark, DE, USA) was reversibly captured $(\sim 15-50$ resonance units [RUs]) by CAP reagent by injecting $1 \mu \mathrm{g} / \mathrm{mL}$ of the $\mathrm{FcRn}$ in phosphate buffer $\mathrm{pH} 7.4$ containing $0.5 \% \mathrm{BSA}$ at $10 \mu \mathrm{L} / \mathrm{min}$. Kinetics and affinity measurements were performed by injecting serial dilutions of the sample in single cycle kinetic mode (SCK) at $25^{\circ} \mathrm{C}$. For hFcRn analysis, the following concentration ranges were used: 4.7-75 $\mathrm{nM}$ for LFBD192 and 24.7-2000 nM for IVIg. For mFcRn analysis, the concentration ranges were $0.2-20 \mathrm{nM}$ for LFBD192 and 3.7-300 nM for IVIg. For Fc $\gamma$ Rs analysis, Histagged hFc $\gamma$ RIIIa (Sinobiological) or mFc $\gamma$ RIV (R\&D Systems) were reversibly captured ( $40-80 \mathrm{RUs})$ on anti-His antibody by injecting $1 \mu \mathrm{g} / \mathrm{mL}$ of each receptor in Tris buffer at $10 \mu \mathrm{L} / \mathrm{min}$. Kinetic measurements were performed by injecting serial dilutions of the sample at $25^{\circ} \mathrm{C}$ in SCK mode for hFc $\gamma \mathrm{RIII}$ and multi cycle kinetic (MCK) mode for mFc $\gamma$ RIV. For hFc $\gamma$ RIIIa, the concentration ranges used were 6.25-100 nM for LFBD192 and $31.25-500 \mathrm{nM}$ for IVIg. For mFc $\gamma \mathrm{RIV}$, the concentration ranges were 1.56-400 nM for LFBD192 and 15.6-4,000 $\mathrm{nM}$ for IVIg. To correct for non-specific binding and bulk effects, the responses obtained from the reference flow-cell and blank injections were subtracted from each interaction curve. Each sample was analyzed at least three times and mean values are presented. For hFcRn, the $\mathrm{pH}$ dependency of association and dissociation were analyzed by injecting a fixed concentration (100 nM) of LFBD192 on 14 RUs of captured hFcRn at different pHs (phosphate buffer at $\mathrm{pH} 6.0$ or 7.4) followed by a dissociation phase in phosphate buffer at the same $\mathrm{pH}$ as during injection or applying a $\mathrm{pH}$ shift using a dual-injection 
mode. For the kinetic analysis of the interaction between hFcrRIIIa and LFBD192, a two-state reaction fit was used. To justify the relevance of this type of fit, two experiments were performed. First, to assess whether the interaction involved one or multiple binding sites, a Scatchard plot was generated by injecting increasing concentrations of LFBD192 (6.25-100 nM) in Tris buffer using the MCK mode over 60 RUs of the captured His-tagged hFc $\gamma$ RIIIa. The second experiment was a link reaction test performed using the link reaction wizard of the Biacore T200 control software, i.e., injection of $250 \mathrm{nM} \mathrm{LFBD} 192$ at $10 \mu \mathrm{L} / \mathrm{min}$ for a contact time of $0,5,3$, and $10 \mathrm{~min}$ and a dissociation time of 10 min over 60 Rus of the captured His-tagged hFc $\gamma$ RIIIIa receptor.

\section{Competitive Binding Assay vs the Fc Receptors Expressed at the Surface of Transfected Cells (FcyRI, Fc $\gamma$ Rlla-H, FcyRIIla-F, and FcRn)}

Binding to Fc receptors expressed on the surface of transfected

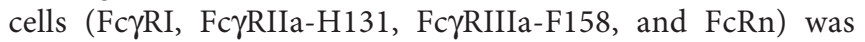
assessed using a competitive binding assay. Binding to Fc $\gamma$ RIIIa was performed as follows: In 96-well plates, $2 \times 10^{5}$ Fc $\gamma$ RIIIaF158-transfected Jurkat cells per well were incubated for $20 \mathrm{~min}$ at $4^{\circ} \mathrm{C}$ with FITC-conjugated anti-Fc $\gamma$ RIIIa $3 \mathrm{G} 8(0.5 \mu \mathrm{g} / \mathrm{mL})$ and various concentrations $(17,34,68,136,272,542,1084$, and $2168 \mathrm{nM})$ of the tested molecules diluted in PBS, pH 7.4. The cells were washed with $100 \mu \mathrm{L}$ of PBS and centrifuged at $1,700 \mathrm{rpm}$ for $3 \mathrm{~min}$ at $4^{\circ} \mathrm{C}$. The supernatant was removed and $300 \mu \mathrm{L}$ of cold PBS was added. FITC-conjugated anti-FcyRIIIa 3G8 residual binding was evaluated by flow cytometry. The mean fluorescence intensity (MFI) values were expressed as percentages, with $100 \%$ being the value obtained with the FITC-conjugated anti-FcyRIIIa $3 \mathrm{G} 8$ alone and $0 \%$ the value obtained in the absence of FITC-conjugated anti-CD16 3G8 (Beckman Coulter). Molecule concentrations required to induce $50 \%$ or $25 \%$ inhibition were calculated using GraphPad Prism 5 software.

Jurkat cells transfected with Fc $\gamma$ RIIa-H or Fc $\gamma R$ I were used to evaluate the binding to the respective receptors in the presence of Alexa-labelled rituximab $(30 \mu \mathrm{g} / \mathrm{mL})$. Dilutions were performed in PBS, pH 7.4.

Jurkat cells transfected with FcRn were used to evaluate the binding to FcRn in the presence of Alexa-labelled rituximab (30 $\mu \mathrm{g} / \mathrm{mL}$ ). Dilutions were performed in PBS, $\mathrm{pH}$ 6.0, as binding to FcRn is $\mathrm{pH}$-dependent.

\section{Inhibition of Anti-D ADCC Against RhD ${ }^{+}$ Red Blood Cells}

Peripheral blood mononuclear cells (PBMCs) purified from buffy coats using Ficoll-Paque density gradient centrifugation were incubated at $1 \times 10^{6}$ cells/well $\left(25 \mu \mathrm{L}\right.$ of cells at $4 \times 10^{7}$ cells $\left./ \mathrm{mL}\right)$ with anti-D antibody $\mathrm{AD} 1$ (LFB) at $50 \mathrm{ng} / \mathrm{mL}$ and $\mathrm{RhD}^{+}$red blood cells $\left(0.5 \times 10^{6}\right.$ cells/well; $25 \mu \mathrm{L}$ of cells at $2 \times 10^{7}$ cells $\left./ \mathrm{mL}\right)$ for $16 \mathrm{~h}$ at $37^{\circ} \mathrm{C}$ (an effector/target ratio of 2:1) in the presence of different concentrations $(1,500,150,15$, and $1.5 \mathrm{nM})$ of the tested molecules. The cytotoxic activity induced by AD1 was measured chromogenically by quantifying the amount of hemoglobin released by the red blood cells in supernatants. The results are expressed as a percentage of specific lysis. The molecule concentrations required to induce $25 \%$ inhibition were calculated using GraphPad Prism 5 software.

\section{Inhibition of Interleukin (IL)-2 Secretion}

CD20-expressing Raji target cells $\left(2.5 \times 10^{5}\right.$ cells/well $)$ were incubated with anti-CD20 mAb (rituximab) at $0.1 \mu \mathrm{g} / \mathrm{mL}$ in the presence of Jurkat cells transfected with Fc $\gamma \mathrm{RI}\left(1.25 \times 10^{5}\right.$ cells/well), $10 \mathrm{ng} / \mathrm{mL}$ phorbol myristate acetate (PMA), and two concentrations (1,950 and $975 \mathrm{nM})$ of IVIg or LFBD192. After $16 \mathrm{~h}$ at $37^{\circ} \mathrm{C}$, the amount of IL-2 released by Fc $\gamma \mathrm{RI}$-transfected Jurkat cells was measured by colorimetry (RD System IL-2 DuoSet ELISA Kit, \#DY202-05) as described (29).

\section{C5a Generation}

Complement activation in human blood was determined by measuring the $\mathrm{C} 5 \mathrm{a}$ concentration. Citrated whole blood (100 $\mu \mathrm{L})$ was incubated at $37^{\circ} \mathrm{C}$ in the presence of hirudin $(6 \mu \mathrm{L}$ at 2,000 U/mL), $\mathrm{CaCl}_{2}(8 \mu \mathrm{L}$ at $75 \mathrm{mM})$, and LFBD192, Fc-trimer or IgG at the concentration of $16.5 \mu \mathrm{M}$ and $33 \mu \mathrm{M}$. Lipopolysaccharide (LPS) $(83 \mu \mathrm{g} / \mathrm{mL})$ and heat-aggregated IgG $\left(65^{\circ} \mathrm{C}\right.$ for $\left.30 \mathrm{~min}\right)$ were used at $2.06,4.12,8.25,16.5$, and $33 \mu \mathrm{M}$ served as positive controls. After overnight incubation, $5 \mu \mathrm{L}$ of $100 \mathrm{mM}$ EDTA was added to stop the reaction. The plates were centrifuged for $2 \mathrm{~min}$ at 1,700 rpm and the amount of C5a in the supernatant was quantified using an ELISA kit (R\&D Systems).

\section{Induction and Activation of Platelet Aggregation}

Citrated whole blood was centrifuged at $200 \times$ g for $10 \mathrm{~min}$ and platelet-rich plasma (PRP) present in the supernatant was collected. Fc fragments $(50 \mu \mathrm{g} ; 25 \mu \mathrm{L}$ at $2 \mathrm{mg} / \mathrm{mL})$ or IgG $(150$ $\mu \mathrm{g} ; 25 \mu \mathrm{L}$ at $6 \mathrm{mg} / \mathrm{mL}$ ) was added to $25 \mu \mathrm{L}$ of PRP for $20 \mathrm{~min}$ at $37^{\circ} \mathrm{C}$. HEPES buffer supplemented with $5 \%$ fetal calf serum (FCS) was used as the negative control and TRAP-6 $(50 \mu \mathrm{M}$ final concentration) as the positive control. PRP was diluted (1/100) with HEPES buffer containing 5\% FCS. The platelet number was quantified according to the number of CD42bpositive cells and CD62P expression (activation marker) was determined by flow cytometry (FC500 Beckman Coulter).

\section{Whole-Blood Cytokine Release Assays}

Increasing concentrations of LFBD192 or IVIG $(6.5,65,650$, and $6,500 \mathrm{nM})$ were incubated with citrated whole blood from healthy human volunteers (EFS Nord de France). After $16 \mathrm{~h}$ of incubation at $37^{\circ} \mathrm{C}$, the blood was centrifuged and the concentrations of cytokines (CXCL10, G-CSF, IL-1 $\beta$, IL-12/ p70, IL-22, IL-5, TNF- $\alpha$, CXCL9/MIG, IFN- $\gamma$, IL-10, IL-1RA, IL-4, and IL-6) released in the supernatants was measured using Magnetic Luminex Assays (human premixed multiple analyte detection kit, \#LXSAHM-13).

\section{Inhibition of Antibody-Mediated Platelet Phagocytosis}

Human THP1 monocytes stably transfected with a chimeric molecule consisting of the human FcyRIIIa-V158 extracellular domain joined to the transmembrane and intracellular domains 
of the gamma chain of the mast/basophil $\mathrm{Fc}$ receptor for IgE (THP1 CD16 ${ }^{+}$cell line) were used. The gamma chain allows Fc $\gamma$ RIIIa membrane expression and provides the ITAM necessary for the transduction of the phagocytosis signal. THP1 CD16+ cells $\left(1 \times 10^{5}\right)$ were pre-incubated with increasing concentrations $\left(6.66 \times 10^{-5}, 6.66 \times 10^{-6}, 6.66 \times 10^{-7}\right.$, and $6.66 \times 10^{-8}$ M) of $10 \%$ IVIg (Iqymune, LFB) or LFBD192 for $30 \mathrm{~min}$ at $37^{\circ} \mathrm{C}$. Platelets were isolated from human blood (EFS, Les Ulis), labeled using the PKH67 Green Fluorescent Cell Linker Kit (general cell membrane labeling, Sigma), and sensitized at $37^{\circ} \mathrm{C}$ for $30 \mathrm{~min}$ with stirring with $1 \mu \mathrm{g} / \mathrm{mL}$ of a human IgG1 anti-CD41 monoclonal antibody (Absolute Antibody) or dilution buffer (non-sensitized platelet control). After incubation, samples were washed twice in Iscove's modified Dulbecco's medium (IMDM) supplemented with $10 \%$ FCS at $1,200 \times g$ for $5 \mathrm{~min}$. Labeled platelets $\left(2 \times 10^{6}\right)$ were added and incubated for 1 at $37^{\circ} \mathrm{C}$. PKH67 labeling was quenched by trypan blue and effector cells were labeled with a fluorescent anti-CD45 antibody (Beckman Coulter). Antibody-mediated platelet phagocytosis was measured by flow cytometry (Gallios Flow Cytometer, Beckman Coulter).

\section{ITP Mouse Model}

Humanized FcRn mice (hFcRn; $\mathrm{mFcRn}^{-/-}$hFcRnTg 276 hemizygotes in a B6 background), 12-16 weeks old, were used for all in vivo ITP-related experiments. These mice carry a knockout mutation for the mouse Fcgrt gene (Fc receptor, IgG, alpha chain transporter) and carry the human FCGRT gene instead, and were obtained by breeding homozygous Tg $276 \mathrm{hFcRn}$ mice with $\mathrm{FcRn}^{-/}$mice purchased from The Jackson Laboratory. After breeding at Charles River facilities (Lyon), the mice were kept in the animal facilities of Friedrich-Alexander-University Erlangen-Nürnberg under specific-pathogen-free conditions in isolated ventilated cages after at least 5 days of acclimation. The mice were maintained according to the guidelines of the National Institutes of Health and German legal requirements. ITP was induced by intraperitoneal injection of $0.3 \mu \mathrm{g} / \mathrm{g}$ body weight 6A6hIgG1 antibody as described (15). Platelet counts were determined before and $24 \mathrm{~h}$ after the injection of antibody diluted 1:4 in PBS in an Advia 120 hematology system (Bayer). Platelet counts before antibody injection were set to $100 \%$. Mice were pretreated by intraperitoneal injection of PBS (control) and of $50 \mathrm{mg} / \mathrm{kg}$ LFBD192, Fc-MST-HN, and the Fc-trimer $2 \mathrm{~h}$ before platelet depletion.

\section{$\mathrm{K} / \mathrm{BxN}$-induced Mouse Model of Acute Arthritis}

Eight-week-old female C57BL/6 mice were purchased from Janvier (France) and maintained at the Artimmune animal facility before experimentation. To induce arthritis (day 0), one intravenous injection of $10 \mu \mathrm{L} / \mathrm{g} \mathrm{K} / \mathrm{BxN}$ serum [prepared as previously described (30) was administered. Three days after serum transfer, a single dose of vehicle (PBS), IVIg (2,000 mg/ $\mathrm{kg}$ ), LFBD192 (25, 50, and 100 mg/kg), Fc-MST-HN (100 mg/kg), or Fc-trimer $(100 \mathrm{mg} / \mathrm{kg})$ was intraperitoneally administered. Dexamethasone $(1 \mathrm{mg} / \mathrm{kg})$ was administered daily and subcutaneously from day 3 until day 9. The therapeutic efficacy of the different molecules was assessed by three different readouts-clinical scores, measurement of IL-6 levels on day 6, and histology (Figure 7A). Arthritis severity was scored via clinical examination by adding the indices of all the paws: 0 , normal paw; 1 , swelling of one joint; 2 , swelling of more than one joint; and 3, severe swelling in the entire paw (28). At the peak of the disease (day 6), blood was drawn from all the animals and collected into tubes. The tubes were centrifuged at 5,000 rpm for $5 \mathrm{~min}$ at $4^{\circ} \mathrm{C}$ and the serum was collected. Serum cytokine concentrations were determined by multiplex immunoassay (MagPix, Bio-Rad). The results are reported as $\mathrm{pg} / \mathrm{mL}$.

The serum concentrations of mouse total IgG were measured by ELISA on days 6 and 10 (Cat-88-50400-22, Thermo Fisher Scientific). A total of $100 \mu \mathrm{L}$ of coating antibody diluted in PBS was incubated overnight at $4^{\circ} \mathrm{C}$. After washing with PBS $+0.05 \%$ Tween 20 and then with PBS only, $250 \mu \mathrm{L}$ of blocking buffer (PBS, $0.1 \%$ Tween 20, and 2\% BSA) was added to each well followed by incubation for $2 \mathrm{~h}$ at room temperature. After washing, $100 \mu \mathrm{L}$ of standards (two-fold serial dilutions, standard curve range: $1.56-100,000 \mathrm{pg} / \mathrm{mL}$ ), samples, and blanks were incubated for $2 \mathrm{~h}$ at room temperature. After washing, $50 \mu \mathrm{L}$ of detection antibody was added and incubated for $3 \mathrm{~h}$ at room temperature. Then, $100 \mu \mathrm{L}$ of substrate (TMB) solution was added and incubated for $15 \mathrm{~min}$ protected from light. The reaction was stopped by the addition of $50 \mu \mathrm{L}$ of stop solution. Optical density (OD) values were measured at $450 \mathrm{~nm}$. The sensitivity of the assay was $1.56 \mathrm{ng} / \mathrm{mL}$.

On day 10 , the mice were euthanized, and the ankle joints were removed and fixed for $12 \mathrm{~h}$ in $10 \%$ paraformaldehyde $(\mathrm{pH}$ 7.2), subsequently incubated in 10\% EDTA, $\mathrm{pH} 7.2$, for 10 days at room temperature to decalcify the bone, washed with PBS, dehydrated, embedded in paraffin, sliced into $3-\mu \mathrm{m}$-thick sections, and stained with hematoxylin and eosin (H\&E). To eliminate potential bias, the slides were scored by two independent observers. The sections were subjectively graded using the following parameters: synovial hyperplasia (pannus formation) severity, cellular exudates, cartilage depletion/bone erosion (each scored 0 [normal] to 3 [severe]), and extent of synovial infiltration (scored $0-5$, with higher scores indicating greater infiltration). The grades for all parameters were subsequently summed to obtain an arthritis index, with results expressed as the median arthritis score (Figure 8).

\section{CAIA Mouse Model}

Eight-twelve-week-old female C57BL/6 mice were obtained from Charles River Laboratories and housed in the Commissariat à l'Energie Atomique Saclay animal facility for experimentation. To induce CAIA (day 0), mice were intravenously injected with an arthritogenic $\mathrm{mAb}$ cocktail comprising four antibodies against collagen II (Arthrogen-CIA 5-Clone Cocktail Kit, Amsbio; 200 $\mathrm{mg} / \mathrm{kg}$ ) under anesthesia as described (25). On day 3, the animals were intraperitoneally injected with LPS (2 mg/kg). On day 5 , the mice were randomized into groups based on disease severity and intraperitoneally dosed with vehicle (PBS), IVIg (1,000 mg/kg), LFBD192 (100 mg/kg), or Fc-trimer (100 mg/kg) (single administration). Dexamethasone was daily and subcutaneously 
administered from day 5 at a dose of $1 \mathrm{mg} / \mathrm{kg}$ until the end of the study. The mice were monitored for 11 days for clinical signs of arthritis (Figure 9A). An analgesic, buprecare $(0.1 \mathrm{mg} / \mathrm{kg}$, administered subcutaneously once a day), was used if mice exhibited signs of discomfort, such as difficulty walking or feeding themselves. Clinical parameters were scored as follows: Arthritis severity in each limb (wrist and ankle) was scored blindly and daily on a scale from 0 to 3 (ankle thickness ( $\mathrm{mm}$ ): score 0: 2.5 $\geq \mathrm{X}$; score 1 : $2.6<\mathrm{X} \leq 2.8$; score 2: $2.9<\mathrm{X} \leq 3.1$; score 3 : $\mathrm{X}>3.1$ and wrist thickness $(\mathrm{mm})$ : score 0 : $1.8 \geq \mathrm{X}$; score 1 : $1.9<\mathrm{X} \leq 2.1$; score 2 : $2.2<\mathrm{X} \leq 2.4$; score 3: $\mathrm{X}>2.4$ ). The final scores corresponded to the sum obtained for each animal paw; each mouse could score a maximum of 12 points $(3 \times 4)$. The measurements were performed vertically for the front legs and horizontally for the rear legs using a digital caliper (Fisherbrand).

\section{Study Approval}

All CAIA experiments were associated with Project No. 17_045 submitted to the Ethics Committee in Animal Experimentation (EAEC) No. 44 and approved by "le ministère de l'éducation nationale, de l'enseignement supérieur et de la recherche" under the number APAFIS \# 9410-201703271734338. All K/BxN experiments were conducted in the Artimmune Laboratory (Orléans, France) and performed in compliance with the guidelines of the French Ministry of Agriculture for experiments with laboratory animals (law 87-848). All animal experiments were approved by the "Ethics Committee for Animal Experimentation of CNRS Campus Orleans” (CCO) under number CLE CCO 2015-1081.

\section{RESULTS}

\section{Design and Screening of Fc Variants Optimized for $\mathrm{hFc} \gamma \mathrm{R}$ and $\mathrm{hFcRn}$ Binding}

We have previously identified key mutations in the Fc region of human IgG1 that increased hFcRn-binding capacity at $\mathrm{pH} 6.0$ using a fully randomized mutagenesis approach combined with a $\mathrm{pH}$-dependent phage display selection process (26). Similar approaches, but including directed mutagenesis, were used to design human IgG1 Fc variants with increased capacity for binding to hFcrRIIIa (unpublished data), which allowed to select one lead variant-A3A-184A (K334N/P352S/A378V/ V397M) - and two key mutations, Y296W and K290G.

To obtain optimized Fc fragment variants with increased binding affinity for both hFcRn and hFc $\gamma$ RIIIa, we attempted two strategies: one involved increasing hFc $\gamma \mathrm{RIII}$ a binding for the previously described hFcRn-optimized variants C6A-74 (V259I/ $\mathrm{N} 315 \mathrm{D} / \mathrm{N} 434 \mathrm{Y})$ and T5A-74 (N315D/A330V/N361D/A378V/ $\mathrm{N} 434 \mathrm{Y}$ ) (26), the other involved increasing hFcRn-binding at $\mathrm{pH} 6.0$ for the hFcrRIIIa-optimized variant A3A-184A. The screening process was done by Bio-Layer Interferometry (BLI) with the Octet system (PALL) comparing binding ratios of different Fc variants $v s$ wild-type Fc related to hFcRn and hFc $\gamma$ RIIIa. Biacore measurements were then performed for the final characterization of the selected lead.

Eight Fc fragment variants were designed, produced in mammalian cells (FreeStyle 293-F cells), and tested for their hFcRn and hFcyRIIIa binding capacity by BLI (at pH 6.0 and 7.4, respectively, Octet system, PALL) together with the nonmutated Fc fragment (wild-type Fc fragment; $\mathrm{rFc}-\mathrm{WT}$ ) and the three lead variants ( $\mathrm{rFc}-\mathrm{C6A}-74, \mathrm{rFc}-\mathrm{T} 5 \mathrm{~A}-74$, and $\mathrm{rFc}-\mathrm{A} 3 \mathrm{~A}-$ 184A). Compared to our previous observations [ (27) and unpublished data], the three lead variants produced as Fc fragments exhibited binding ratios similar to those of other IgG1 formats (Table 1). For instance, the rFc-C6A-74 and rFcT5A-74 variants displayed an optimized ability to bind hFcRn, and not hFcrRIIIa, with increased ratios of 5.6 and 9.0, respectively, compared with that for $\mathrm{rFc}-\mathrm{WT}$. As expected, the rFc-A3A-184A variant showed an optimized capacity for binding

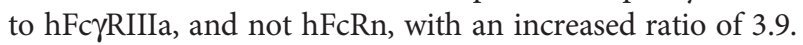

The T5A-74 variant was first simplified by removing the A330V mutation (T5A-74A variant), which was shown to selectively decrease its binding to $\mathrm{Clq}$ but not to other $\mathrm{Fc}$ receptors (27) and unpublished data]. Indeed, the rFc-T5A-74 and $\mathrm{rFc}$-T5A-74A variants exhibited similar binding capacities for hFcRn and hFc $\gamma$ RIIIa. The Y296W and K290G mutations, previously selected on hFc $\gamma$ RIIIa, were added to the three mutants: C6A-74 (rFc-C6A-74W and rFc-C6A-74G), T5A-74A

TABLE 1 | KD determined by BLI (Octet device) of 8 new mutants vs initial variants at pH6.0 for hFCRn and pH7.4 for hFcyRllla (KD determined as means of 3 experiments).

\begin{tabular}{|c|c|c|c|c|c|c|c|}
\hline Molecule & Mutations & \multicolumn{3}{|c|}{ KD (nM) } & \multicolumn{3}{|c|}{ Ratio KD WT/variant } \\
\hline $\mathrm{rFC}-\mathrm{WT}$ & & 36.5 & 8.2 & 504 & 75.0 & 1.0 & 1.0 \\
\hline $\mathrm{rFc}-\mathrm{C} 6 \mathrm{~A}-74$ & V259I/N315D/N434Y & 6.4 & 0.5 & 352 & 44.5 & 5.6 & 1.4 \\
\hline rFc-C6A-74W & V259I/Y296W/N315D/N434Y & 12.3 & 0.4 & 325.5 & 48.8 & 2.9 & 1.5 \\
\hline rFc-C6A-74G & K290G/N259I/N315D/N434Y & 9.5 & 0.9 & 234 & 15.6 & 3.8 & 2.2 \\
\hline rFC-T5A-74 & N315D/A330V/N361D/A378V/N434Y & 4 & 1.9 & 317 & 45.3 & 9.0 & 1.6 \\
\hline rFc-T5A-74AG & K290G/N315D/N361D/A378V/N434Y & 18.9 & 1.9 & 165 & 15.6 & 1.9 & 3.1 \\
\hline rFc-A3A-184A & K334N/P352S/A378VN397M & 29.4 & 2.2 & 129 & 5.7 & 1.2 & 3.9 \\
\hline rFc-A3A-184E & Y296W/K334N/P352S/A378VN397M & 53.8 & 4.9 & 122 & 26.9 & 0.7 & 4.1 \\
\hline rFC-A3A-184AG & K290G/K334N/P352S/A378V/N397M & 23.6 & 8.5 & 448 & 66.5 & 1.5 & 1.1 \\
\hline rFC-A3A-184AY & K334N/P352S/A378VN397M/N434Y & 7.8 & 0.0 & 132 & 14.1 & 4.6 & 3.8 \\
\hline
\end{tabular}


(rFc-T5A-74MA and rFc-T5A-74AG), and A3A-184A (rFcA3A-184E and rFc-A3A-184AG). The Y296W mutation further improved hFc $\gamma$ RIIIa for all variants but at the expense of hFcRn binding for the rFc-C6A-74 and rFc-A3A-184A variants, whereas the addition on the $\mathrm{rFc}-\mathrm{T} 5 \mathrm{~A}-74$ variant had little effect on hFcRn binding. Similarly, the addition of the K290G mutation had diverse effects depending on the parental variant, i.e., it increased binding to hFc $\gamma$ RIIIa but decreased binding to $\mathrm{hFcRn}$ when added to the $\mathrm{rFc}-\mathrm{C} 6 \mathrm{~A}-74$ and $\mathrm{rFc}-\mathrm{T} 5 \mathrm{~A}-$ $74 \mathrm{~A}$ variants and decreased binding to both $\mathrm{Fc}$ receptors when added to the rFc-A3A-184A variant. These results highlighted the difficulty of rational design of the variants, as mutations can have adverse effects depending on the mutations already introduced. Finally, the N434Y mutation, which was used in both the $\mathrm{hFcRn}$-optimized $\mathrm{rFc}-\mathrm{C} 6 \mathrm{~A}-74$ and $\mathrm{rFc}-\mathrm{T} 5 \mathrm{~A}-74$ variants and was localized in the $\mathrm{hFcRn}$ binding site, was added to the $\mathrm{rFc}-\mathrm{A} 3 \mathrm{~A}-184 \mathrm{~A}$ variant. The resulting combination variant $\mathrm{rFc}-$ A3A-184AY exhibited the best binding properties towards both hFcRn and hFcrRIIIa (Table 1).

Based on these results, the Y296W mutation was added to the $\mathrm{rFc}-\mathrm{A} 3 \mathrm{~A}-184 \mathrm{AY}$ variant to further improve its binding affinity for hFc $\gamma$ RIIIa, while maintaining its optimization for $\mathrm{hFcRn}$, yielding our lead variant, named LFBD192 (Y296W/K334N/P352S/ A378V/V397M/N434Y). Real-time surface plasmon resonance (SPR) measurements were then performed with Biacore to analyze the LFBD192 interaction $v$ IVIg at pH 6.0 with hFcRn and $\mathrm{mFcRn}$ and at $\mathrm{pH} 7.4$ with hFcrRIIIa and its mouse orthologue mFcyRIV (Figure 1 and Table 2). A comparative analysis of the sensorgrams showed different behaviors for IVIg and LFBD192 (Figure 1). The fast association/dissociation phase observed for the interaction between IVIg and hFcRn agreed best with the steady-state interaction model, while LFBD192 interaction followed a simple first-order (1:1) Langmuir model. As indicated by the $K_{\mathrm{D}}$ values, the LFBD192 affinity for hFcRn was more than two orders of magnitude higher than that of IVIg (3.5 nM vs $469 \mathrm{nM}$, respectively) (Figure 1). Furthermore, SPR experiments were conducted to analyze the $\mathrm{pH}$ dependency of the interaction between LFBD192 and hFcRn. As shown in Figure 1, LFBD192 is bound to hFcRn at $\mathrm{pH} 6.0$, but not at $\mathrm{pH}$ 7.4. Once a complex was formed at $\mathrm{pH}$ 6.0, LFBD192 dissociated instantly from $\mathrm{hFcRn}$ when the $\mathrm{pH}$ was shifted to 7.4, whereas a slower dissociation rate was observed at $\mathrm{pH}$ 6.0.

LFBD192 and IVIg also behaved differently in their interaction with $\mathrm{mFcRn}$. Although both interactions followed a first-order (1:1) Langmuir model, LFBD192 had a significantly lower off rate, resulting in a more than two orders of magnitude higher affinity for $\mathrm{mFcRn}$ compared with IVIg (Figures 1C, D). Our results showed that LFBD192 has a higher affinity than IVIg for both human and mouse FcRn receptors. Also, the affinity of LFBD192 for $\mathrm{mFcRn}$ was 35 times higher than that for the human receptor, a difference that was driven by the low dissociation rate.

For the interaction with hFc $\gamma$ RIIIa, IVIg followed a simple first-order (1:1) Langmuir model, while a biphasic dissociation phase was observed for LFBD192, which rendered the use of the (1:1) Langmuir model unsuitable for the analysis (Figures 1E, F). The choice of the two-state reaction model was supported by the linked test results, which showed a linked reaction (the dissociation rate is dependent on the contact time), and a Scatchard plot, which showed a linear behavior favoring the existence of a single binding site on the analyte. This observation indicated that a conformational change might stabilize the LFBD192-hFc $\gamma$ RIIIa complex during the interaction, resulting in nearly one $\log _{10}$ higher affinity compared with IVIg.

The interaction of LFBD192 and IVIg with mFc $\gamma$ RIV both followed a simple first-order (1:1) Langmuir model (Figures 1G, H). The affinity of LFBD192 for mFc $\gamma$ RIV was nine-fold lower than that for hFcyRIIIa; however, the increase in the affinity of LFBD192 in comparison with IVIg was proportionally similar for mFc $\gamma$ RIV and hFc $\gamma$ RIIIa.

The LFBD192 produced by CHO-S (Freedom CHO-S) and purified in a 2-step chromatography process was monomeric with an apparent molecular weight of $51.4 \mathrm{kDa}$, as determined by size-exclusion chromatography. LC-MS analysis of the deglycosylated and reduced LFBD192 resulted in two main forms, namely, an intact Fc (25658 Da) and a C-terminal lysine-clipped form (25531 Da), which validated the polypeptide sequence (theoretical $25656 \mathrm{Da}$ ). N-glycan analysis revealed biantennary structures composed primarily of G0F glycan species, which are commonly found in $\mathrm{CHO}$-derived antibodies (data not shown).

\section{LFBD192 Blocked Anti-Fc Receptor Molecules on the Different hFcyRs with High Efficacy}

To further explore the interaction between LFBD192 and the Fc receptors, the ability of both LFBD192 and IVIg to compete with a mAb specific for hFc $\gamma$ RIIIa (3G8 mAb) or a generic mAb competing for $\mathrm{Fc}$ receptors through its $\mathrm{Fc}$ portion were compared in a competitive binding assay using the different human Fc gamma receptors expressed on the surface of cells from different lines, namely, Jurkat-Fc $\gamma$ RIIIa-F158, HEK-

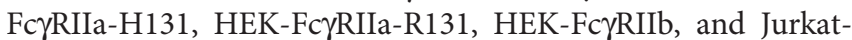
Fc $\gamma$ RI. LFBD192 has been compared to several molecules: IVIg widely used to treat immune complex driven inflammatory diseases, a modified Fc (Fc-MST-HN) targeting only FcRn (2) and a trivalent $\mathrm{Fc}$ (Fc-trimer) described to bind with high avidity to all $\mathrm{Fc}$ receptors (30). The two latter molecules were in-house designed according to information provided in publications (2, 30) and patents (WO 2016142782 and WO 2015168643) and produced in mammalian cells (HEK293). The competition assay was performed between LFBD192, IVIg, Fc-MST-HN, and the Fc-trimer and two different labeled IgG1 as anti-Fc receptors depending on the Fc receptors studied (Table 3). Rituximab was used for HEK-Fc $\gamma$ RIIa-H131, HEK-Fc $\gamma$ RIIa-R131, HEKFc $\gamma R I I b$, and Jurkat-Fc $\gamma R I$ and the $3 \mathrm{G} 8$ anti-Fc $\gamma$ RIIIa mAb was used for Jurkat-Fc $\gamma$ RIIIa-F158. Experiments with Fc $\gamma$ Rtransfected cells were performed at $\mathrm{pH}$ 7.4. As expected, LFBD192 was more potent than IVIg in its ability to inhibit a competitor IgG1 (Table 3). The IC50 of IVIg against Fc $\gamma$ RIIIaF158, Fc $\gamma$ RIIa-R131, Fc $\gamma$ RIIb, and Fc $\gamma R I$ was 10-15-fold higher than that of LFBD192. The IC50 of LFBD192 vs IVIg was lower (4.5 times) for the Fc $\gamma$ RIIa variant H131. Fc-MST-HN exhibited

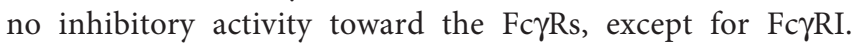


A

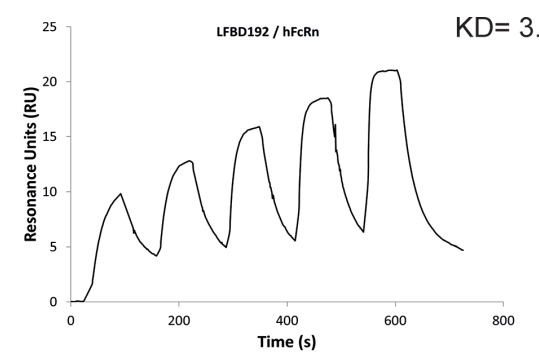

C

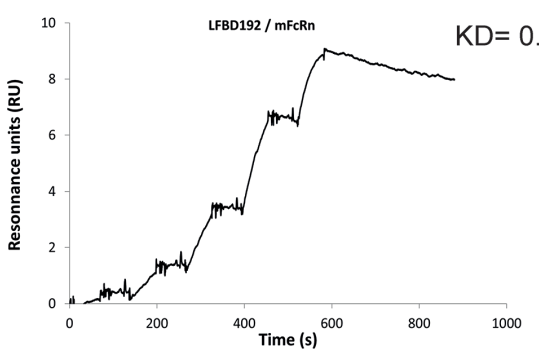

$E$

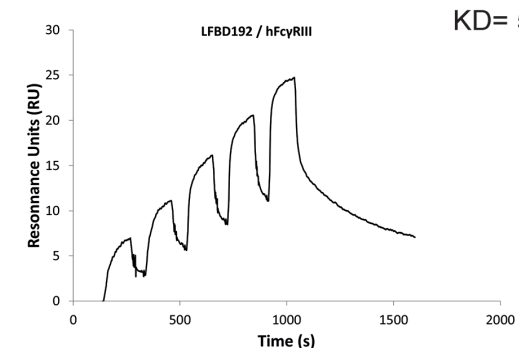

G

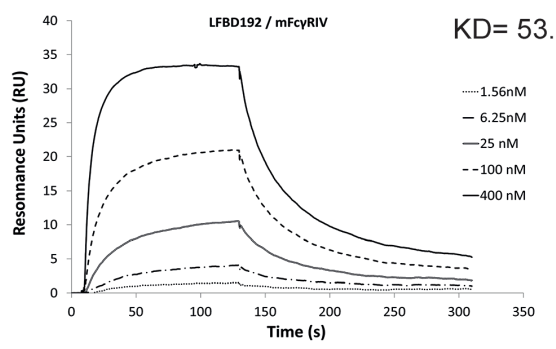

I

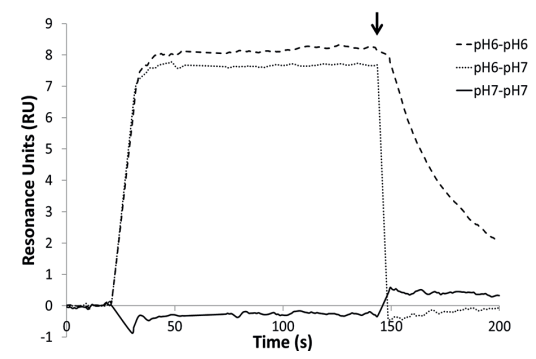

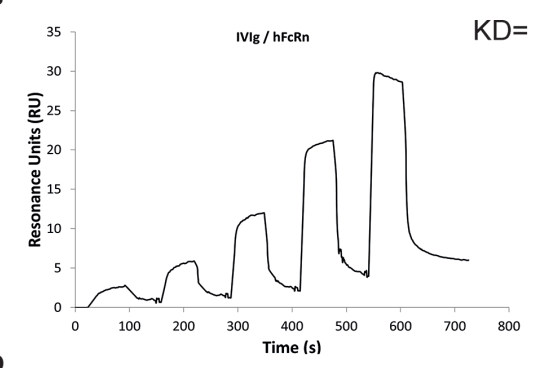

D
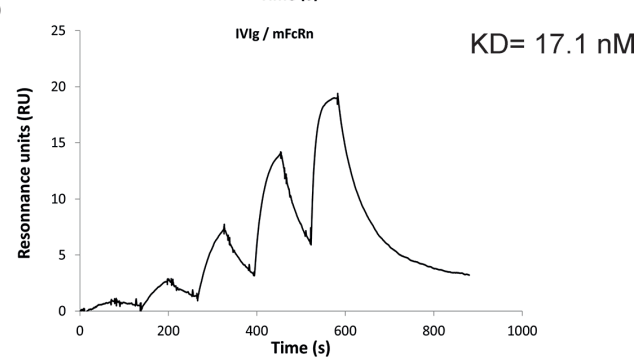

$\mathbf{F}$

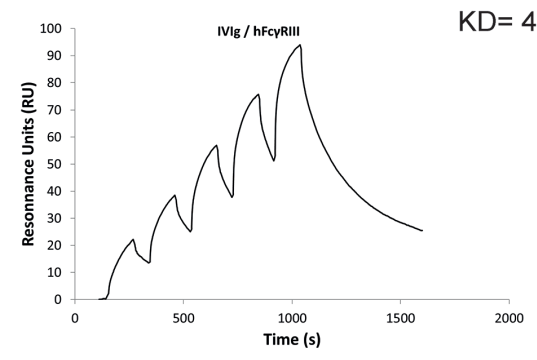

H

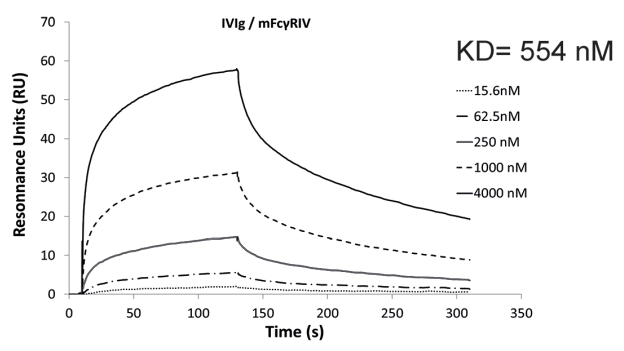

FIGURE 1 | Biacore analysis of LFBD192 binding to hFcRn and hFcyRllla. Representative surface plasmon resonance (SPR) sensorgrams obtained for (A) the injection of LFBD192 at 4.7-75 nM on 25 resonance units (RUs) of immobilized hFcRn using phosphate at pH 6.0; (B) the injection of IVIg at 24.7-2,000 $\mathrm{nM}$ on $25 \mathrm{RUs}$ of immobilized hFcRn using phosphate at pH 6.0; (C) The injection of LFBD192 at 0.2-20 nM on $~ 50$ RUs of immobilized mFcRn using phosphate buffer at pH 6.0; (D) The injection of IVlg at 3.7-300 nM on 50 RUs of immobilized mFcRn using phosphate buffer at pH 6.0. (E) The injection of LFBD192 at 6.25$100 \mathrm{nM}$ on 40 RUs of immobilized hFcyRllla using Tris buffer at pH 7.4; (F) the injection of IVIg at 31.25-500 nM on 80 RUs of immobilized hFcyRllla using Tris buffer at pH 7.4; (G) The injection of LFBD192 at 1.56-400 nM on 40 RUs of immobilized mFcyRIV using Tris buffer at pH 7.4; (H) the injection of IVlg at 15.64,000 nM on 40 RUs of immobilized mFcyRIV using Tris buffer at pH 7.4; (I) $100 \mathrm{nM}$ injections of LFBD192 on 14 RUs of immobilized hFcRn in phosphate buffer $\mathrm{pH} 7.4$ followed by a dissociation phase at pH 7.4 (solid line), phosphate buffer pH 6.0 followed by a dissociation phase at pH 6.0 (dotted line), or phosphate buffer $\mathrm{pH} 6.0$ followed by a dissociation phase at pH 7.4 (dashed line) using dual injection mode. The end of the association phase is indicated by an arrow. 
TABLE 2 | Equilibrium dissociation constants of LFBD192 vs IVIg regarding hFcRn, mFcRn, hFcyRIIla and mFcyRIV at pH6.0 for FcRn (mouse and human) and pH7.4 for hFc $\gamma R$ IIlla and $\mathrm{mFc} \gamma \mathrm{RIV}, \chi 2$ values are provided as an assessment of the goodness of fit.

\begin{tabular}{|c|c|c|c|c|c|c|c|c|c|c|c|c|}
\hline \multirow[t]{2}{*}{ Sample } & \multicolumn{3}{|c|}{ hFcRn } & \multicolumn{3}{|c|}{ mFcRn } & \multicolumn{3}{|c|}{ hFcyRIIla } & \multicolumn{3}{|c|}{ mFcyRIV } \\
\hline & KD (nM) & CV (\%) & $\chi^{2}$ & KD (nM) & CV (\%) & $\chi^{2}$ & $\mathrm{KD}(\mathrm{nM})$ & CV (\%) & $\chi^{2}$ & KD (nM) & CV (\%) & $\chi^{2}$ \\
\hline LFBD192 & $3.5^{\mathrm{a}}$ & 17 & 0.5 & $0.1^{a}$ & 12.6 & 0.2 & $5.9^{c}$ & 21 & 0.4 & $53.8^{a}$ & 8.8 & 0.6 \\
\hline IVIg & $469^{b}$ & 9.8 & 0.1 & $17.1^{\mathrm{a}}$ & 4.2 & 7.6 & $40^{a}$ & 0.7 & 6.9 & $554^{a}$ & 15.2 & 1.5 \\
\hline
\end{tabular}

${ }^{a}$ The kinetic constant was obtained using the simple first-order (1:1) Langmuir bimolecular interaction model.

${ }^{b}$ The affinity constant was obtained using the steady state model.

${ }^{c}$ The kinetic constant was obtained using the two state reaction model. The use of this model has been demonstrated by a linked reaction test and a linear Scatchard plot (data not shown).

In contrast, the trimeric Fc avidity allowed a higher potency compared to LFBD192 one for Fc $\gamma$ Rs except for Fc $\gamma$ RI.

\section{LFBD192 Blocked Anti-Fc Receptor Molecules on FcRn with High Efficacy}

LFBD192 interactions with FcRn receptors and competition with immunoglobulins were explored using a Jurkat cell line that overexpressed FcRn (Figure 2). The ability of LFBD192 to compete with an antibody (rituximab) was compared to three molecules at pH 6.0: IVIg, Fc-MST-HN that targets only FcRn (2), and Fc-trimer, reported to bind with high avidity to all Fc receptors (25). The strongest inhibitory effect was observed for LFBD192 and Fc-MST-HN (Figure 2). The LFBD192 and FcMST-HN IC50 ratios versus IVIg were 90 and 96 times, respectively (Table 3). Surprisingly, the Fc-trimers with an IC50 value of 23 were not as efficient as LFBD192 $($ IC50 $=15)$ or Fc-MST-HN (IC50 = 14).

\section{LFBD192 Protects Against IC-Mediated Cell Activation}

The ability of LFBD192 to protect against antibody-targeted cell lysis by effector cells or effector cell activation was tested in three different in vitro models. In the first two models, the ability of LFBD192 to protect against anti-D-mediated red blood cell lysis (Figure 3A) and antibody-mediated platelet phagocytosis was tested (Figure 3B). Red blood cells were incubated with an anti$\mathrm{D}$ mAb to obtain anti-D-opsonized red blood cells and the ability of the tested molecules to inhibit human PBMC effector-

TABLE 3 | Determination of inhibitory concentration at 50\% (IC 50) between IgG1 and LFBD192, IVIg, FC-MST-HN, and Fc-trimer on cell lines transfected with hFcRn or hFcRs (IC50 calculated with mean of 2 experiments).

\begin{tabular}{|c|c|c|c|c|c|}
\hline Transfected cell line & $\lg G$ & LFBD192 & \multicolumn{3}{|c|}{ IC 50 (nM) } \\
\hline Jurkat-FcRn & Rituximab & 15 & 1356 & 14 & 23 \\
\hline HEK-FcyRlla-H & Rituximab & 147 & 671 & $>2170$ & 12 \\
\hline HEK-FcyRlla-R & Rituximab & 132 & 1308 & $>2170$ & 17 \\
\hline HEK-FcyRllb & Rituximab & 55 & 761 & $>2170$ & 16 \\
\hline
\end{tabular}

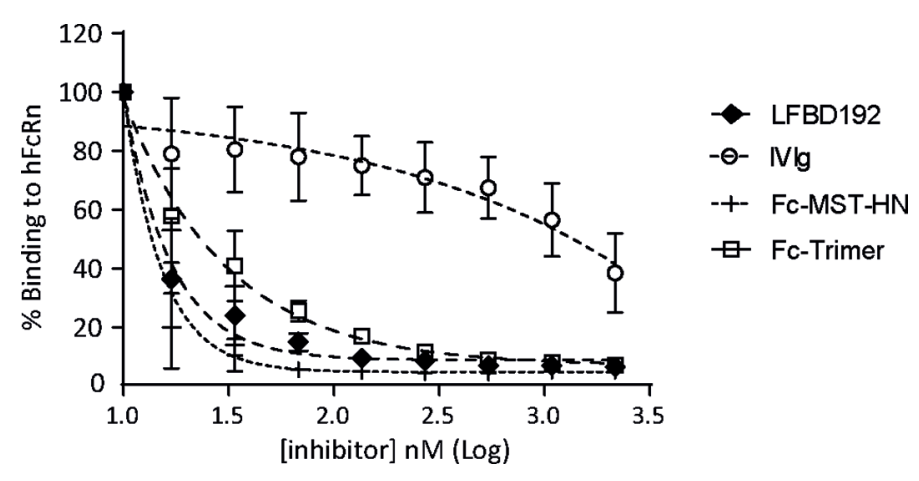

FIGURE 2 | LFBD192 blocks the binding of IgG to FcRn. The binding of LFBD192, IVlg, Fc-MST-HN, and the Fc-trimer to human FcRn expressed at the surface of Jurkat cells measured at $\mathrm{pH} 6.0$ in a competitive assay in the presence of Alexa-labeled rituximab $(30 \mu \mathrm{g} / \mathrm{mL}$ ) (data represent the means \pm SEM of two experiments, each experiment performed in triplicates). 
A

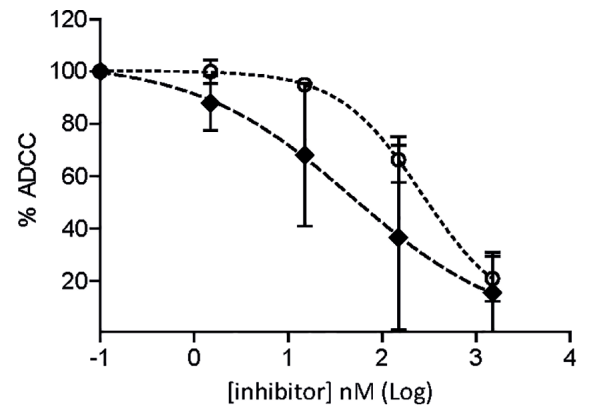

B

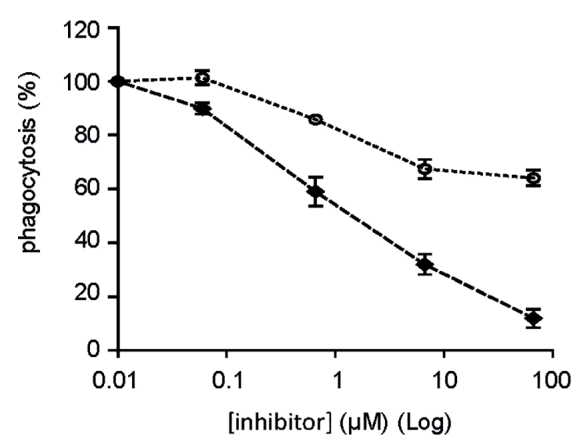

C

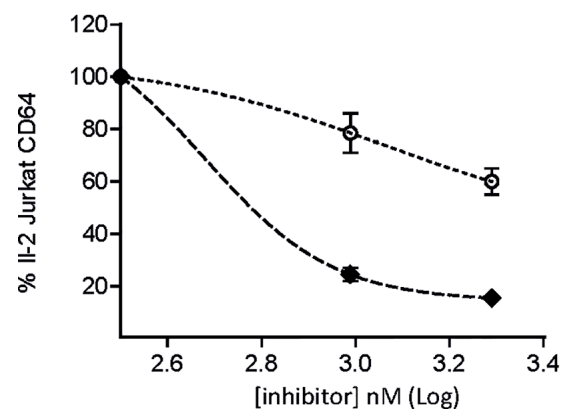

FIGURE 3 | LFBD192 vs IVIg in three models of inhibition of immune complex-mediated cell lysis. (A) Percentage of antibody-dependent cellmediated cytotoxicity (ADCC) inhibition for anti-D antibody-treated $\mathrm{O}^{+}$human red blood cells (data are the means of two experiments from different human donors, each experiment performed in triplicates). (B) Percentage of phagocytosis inhibition of human anti-platelet lgG1 (anti-CD41)-treated fluorescence-labeled platelets obtained from human donors mediated by FcyRllla-transfected THP1 cells with $6.66 \times 10^{-5}, 6.66 \times 10^{-6}, 6.66 \times 10^{-7}$, and $6.66 \times 10^{-8} \mathrm{M}$ of $10 \% \mathrm{IVIg}$ or LFBD192 (data represent the means \pm SEM of three experiments from three different human donors, each experiment performed in duplicates). (C) Percentage of inhibition of FcyRI-mediated IL-2 secretion by FcyRl-expressing Jurkat T cell lymphomas (CD20-negative) in co-culture with CD2O-expressing Raji cells rituximab/Raji cells complex (data represent the means \pm SEM of two experiments from different human donors, each experiment performed in triplicates).

mediated lysis was determined. LFBD192 showed the greatest protective effect with an IC50 of 97 vs 351 for IVIg. In the second test, THP1 CD16 ${ }^{+}$cells were incubated with human monoclonal anti-platelet IgG1 (anti-CD41) and fluorescently labeled platelets obtained from human donors (Figure 3B). Interestingly, LFBD192 at $0.6 \mu \mathrm{M}$ demonstrated the same inhibitory effect as
IVIg at $60 \mu \mathrm{M}$, suggesting that LFBD192 was 100 times more potent than IVIg at inhibiting human antibody-mediated platelet phagocytosis (Figure 3B). The observed inhibitory effects were mediated by Fc $\gamma \mathrm{R}$ blocking.

The ability of LFBD192 to inhibit IC-mediated cell activation was also tested. CD20-expressing Raji target cells were incubated with rituximab in the presence of Jurkat cells overexpressing Fc $\gamma$ RI. After $16 \mathrm{~h}$, the amount of IL-2 released by the Jurkat cells was measured. LFBD192 was found to be substantially more potent than IVIg at blocking IC engagement (Figure 3C). Indeed, the LFBD192 inhibitory concentration at 25\% was 2.5fold higher than that of IVIg (442 vs $1106 \mathrm{nM}$ ), and the IC50 of LFBD192 was $600 \mathrm{nM}$; however, the IVIg IC50 could not be calculated (over $1950 \mathrm{nM}$ ).

\section{LFBD192 Does Not Trigger Immune Reactions In Vitro}

We next addressed a safety consideration regarding potential complement and platelet activation and Fc $\gamma \mathrm{R}$ cross-linking that could trigger immune cell activation and cytokine release similar to that observed with IgG aggregates (Figures 4,5). The potential activation of the complement cascade was assessed by the determination of C5a concentration (Figure 4A). LFBD192 (16.5 and $33 \mu \mathrm{M})$ was incubated with human whole blood and its ability to induce C5a generation was compared to that of LPS), Fc-trimer (16.5 and $33 \mu \mathrm{M})$ aggregated $\operatorname{IVIg}(2.06,4.12,6.25$, 16.5, $33 \mu \mathrm{M}))$, and IVIg $(22.7 \mu \mathrm{M})$. Unlike LPS and aggregated IVIg, which served as positive controls, LFBD192 did not generate an increase of $\mathrm{C} 5 \mathrm{a}$ in whole blood.

Platelets expressing FcyRIIa could potentially be activated by engagement with LFBD192 optimized for binding to this receptor. Potential platelet activation was tested by incubating LFBD192 or IVIg in PRP from 2 healthy blood donors and then determining the expression levels of CD62P, a platelet activation marker (p-selectin) (Figure 4B). Neither LFBD192 nor IVIg at 20 $\mu \mathrm{M}$ induced the expression of CD62P, in contrast to that observed with incubation with the positive control TRAP-6. These results demonstrated that, although LFBD192 was optimized for Fc $\gamma$ RIIa binding, it did not promote platelet activation.

To investigate if LFB192 could induce a cytokine release syndrome, increasing concentrations of LFB192 (6.5, 65, 650, and $6,500 \mathrm{nM}$ ) were incubated with human whole blood, and the effects on the concentrations of a variety of cytokines were compared with those of incubation with the same concentrations of IVIg and Fc-trimer (Figure 5). Importantly, no expression of most of the cytokines assessed (proinflammatory G-CSF, IL-1 $\beta$, IL-12/p70, TNF- $\alpha$, CXCL9/MIG, and IL- 6 and anti-inflammatory IL-4, IL-5, IL-10, and IL-22) was detected after $24 \mathrm{~h}$ of incubation (data not shown). Only low levels of the pro-inflammatory cytokines CXCL10 and IFN- $\gamma$ and the anti-inflammatory cytokine IL-1RA were observed, but at a similar or lower level than with IVIg or the Fc-trimer.

In summary, LFBD192 showed a good in vitro safety profile relating to platelet and complement activation. Furthermore, in an in vitro human whole blood safety assay, incubation with LFBD192 did not result in cytokine release. 
A

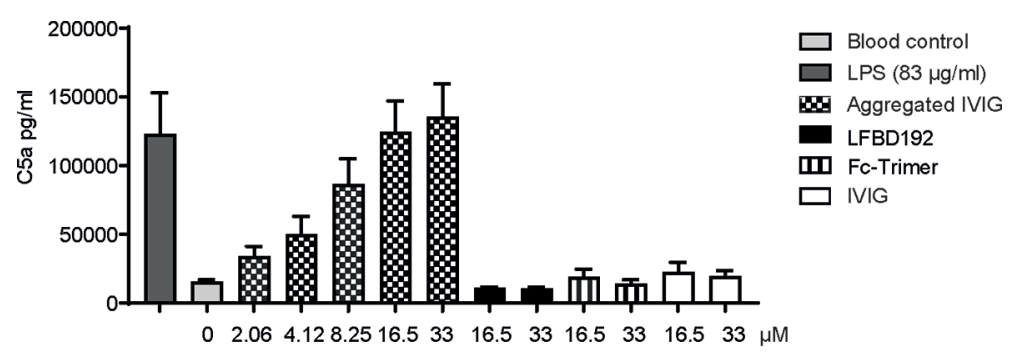

B
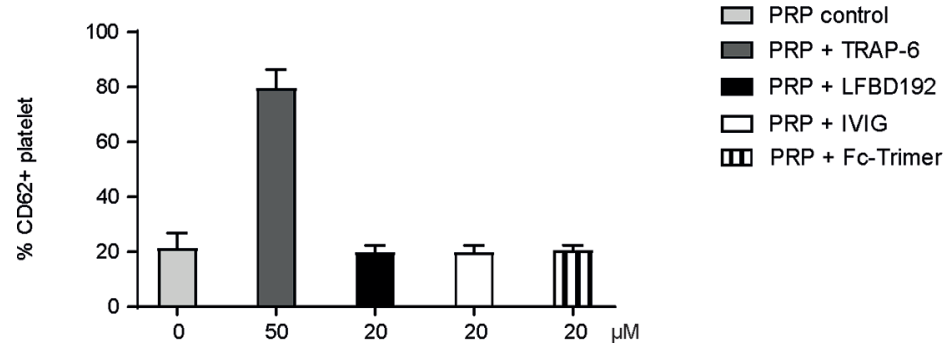

FIGURE 4 | LFBD192 does not trigger in vitro immune reactions relating to complement and platelet activation. (A) C5a generation in human whole blood in response to lipopolysaccharide (LPS) $(83 \mu \mathrm{g} / \mathrm{mL})$, aggregated IVlg $(2.06,4.12,6.25,16.5,33 \mu \mathrm{M})$, LFBD192 (16.5 and $33 \mu \mathrm{M})$, FC-trimer (16.5 and $33 \mu \mathrm{M})$ and IVlg $(16.5$ and $33 \mu \mathrm{M})$ was quantified by ELISA. Data are mean \pm SEM of 4 experiments from 4 different human donors, each experiment performed in duplicates.

(B) Platelet activation in response to TRAP-6 $(50 \mu \mathrm{M}$, positive control), LFBD192 $(20 \mu \mathrm{M})$, and IVlg $(20 \mu \mathrm{M})$. Bars represent the means of CD62P expression ( \pm SD) as measured by flow cytometry of 2 experiments from 2 different human donors, each experiment performed in duplicates.

\section{LFBD192 Potency in Models of Autoimmune Disease}

LFBD192 efficacy was tested in vivo in three different antibodymediated autoimmune mouse models, one as preventive treatment (ITP model; Figure 6) and two as therapeutic administration (K/ BxN and CAIA; Figures 7, 8, respectively). In all tests, LFBD192 was compared to IVIg, Fc-MST-HN, and the Fc-trimer (30). The optimized affinity of LFBD192 for mouse Fc receptors (mFcRn and $\mathrm{mFc} \gamma \mathrm{RIV}$ ) allowed validating of the testing in a mouse Fc receptor context. An ITP model was induced in humanized FcRn mice by intraperitoneal injection of a mouse anti-platelet antibody containing a human Fc fragment (6A6-hIgG1) (15) as a platelet depleting antibody (Figure 6). As expected, the depleting antibody $(0.3 \mu \mathrm{g} / \mathrm{g})$ in the presence of PBS (which served as a negative control) elicited a $36 \%$ decrease in thrombocyte number. Interestingly, LFBD192 administration at $50 \mathrm{mg} / \mathrm{kg} 2 \mathrm{~h}$ before platelet depletion restored the platelet count to $81 \%$, similar to that seen with the Fc-trimer (80\%). In contrast, at the same dose, FcMST-HN could not restore platelet levels, suggesting that targeting only FCRn was not sufficient to protect platelets in this ITP prevention model. The 4 and $24 \mathrm{~h}$ study points were probably too short to allow the observation of the physiological effect of lowering anti-platelet antibody levels via FcRn blocking.

The effect of LFBD192 was also tested in two mouse models of acute inflammatory arthritis, in which ICs and Fc $\gamma$ Rs have been shown to be implicated $(1,14,15)$. The therapeutic efficacy of
LFBD192 was first evaluated in the $\mathrm{K} / \mathrm{BxN}$-induced arthritis model (Figure 7). Inflammation was induced in mouse joints via the transfer of serum from arthritogenic mice to C57-BL6 mice. Three days after serum injection, the mice were treated with LFBD192, IVIg, Fc-MST-HN, or Fc-timer (Figure 7A). All the tested compounds significantly reduced clinical scores compared with those obtained for the $\mathrm{K} / \mathrm{BxN}+$ vehicle group (Figure $\mathbf{8 B}$ ). A dose-dependent reduction in clinical scores was observed in mice treated with LFBD192 at 25, 50, and $100 \mathrm{mg} / \mathrm{kg}$ (Figure 7B). A slightly higher reduction in clinical scores was observed for LFBD192 when compared with the Fc-trimer and Fc-MST-HN at $100 \mathrm{mg} / \mathrm{kg}$ and IVIg at 2,000 $\mathrm{mg} / \mathrm{kg}$; however, the reductions were not statistically significant. At $25 \mathrm{mg} / \mathrm{kg}$, LFBD192 elicited a reduction in clinical scores equivalent to that for Fc-MST-HN at $100 \mathrm{mg} / \mathrm{kg}$.

Total circulating mouse IgG dosages were determined at days 6 and 10, three and seven days after drug treatments, respectively. The levels of endogenous IgGs were higher in non-treated mice with $\mathrm{K} / \mathrm{BxN}$-induced arthritis than in healthy control. LFBD192 at 25 and $100 \mathrm{mg} / \mathrm{kg}$ doses, IVIg at 2,000 mg/ $\mathrm{kg}$, and Fc-MST-HN at $100 \mathrm{mg} / \mathrm{kg}$ elicited a more than $50 \%$ reduction in circulating mouse IgG relative to non-treated $\mathrm{K} /$ BxN mice (Figure 7C).

The level of the inflammatory cytokine IL- 6 was analyzed at the peak of the disease (day 6). LFBD192 at $25 \mathrm{mg} / \mathrm{kg}$ promoted a significant reduction in the increase of IL-6 secretion compared with that in the $\mathrm{K} / \mathrm{BxN}+$ vehicle group 


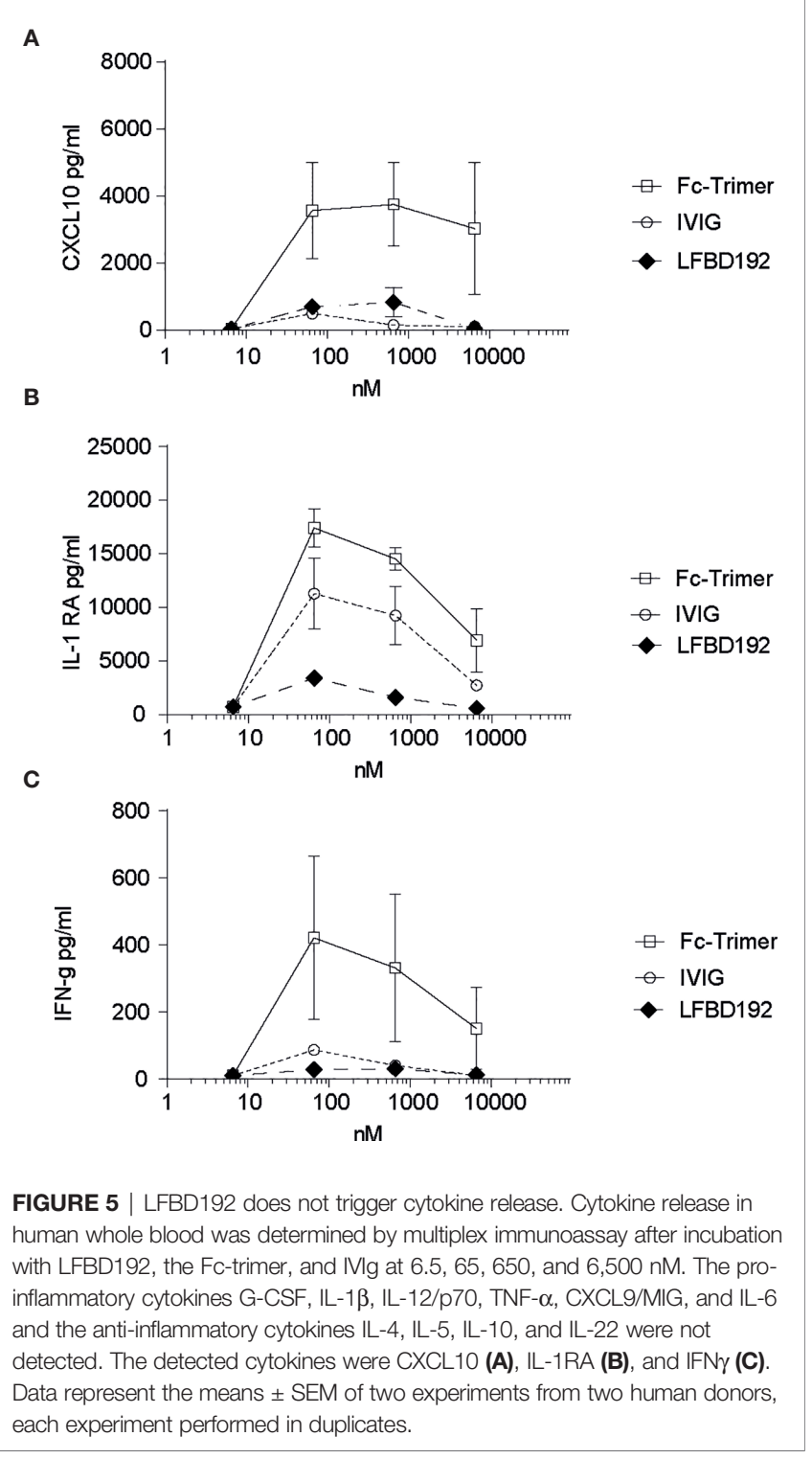

(Figure 7D). A non-significant reduction in IL-6 concentrations was observed for LFBD192 at 50 and $100 \mathrm{mg} / \mathrm{kg}, \mathrm{Fc}-\mathrm{MST}-\mathrm{HN}$ at $100 \mathrm{mg} / \mathrm{kg}$, IVIg at 2,000 mg/kg, and the Fc-trimer at $100 \mathrm{mg} / \mathrm{kg}$.

Histopathological analysis showed that compared with the $\mathrm{K} / \mathrm{BxN}+$ vehicle group, treatment with LFBD192 (50 and $100 \mathrm{mg} / \mathrm{kg}$ ) or Fc-MST-HN (100 mg/kg) exerted significant protective effects against inflammation in the joints, synovial tissue expansion, and bone erosion (Figure 8). In contrast, IVIg at $2,000 \mathrm{mg} / \mathrm{kg}$ and the Fc-trimer at $100 \mathrm{mg} / \mathrm{kg}$ did not significantly affect the histological score.

LFBD192 was also tested in a CAIA model in which inflammation was triggered by the administration of arthritogenic anti-collagen II antibodies (Figure 9A). In a first experiment, mice were treated with IVIg at $1000 \mathrm{mg} / \mathrm{kg}$ and Fctrimer at $100 \mathrm{mg} / \mathrm{kg} 5$ days after antibody injection and daily with $1 \mathrm{mg} / \mathrm{kg}$ dexamethasone (Figure 9B). The dose for each molecule was determined to be comparable to that previously reported (25). The mice from the group injected with arthritogenic antibodies without treatment developed acute arthritis, reaching a clinical score close to 7.5. From day 6, all treatments decreased the clinical scores, although the Fc-trimer elicited the best results, as previously described (25). In a second experiment, LFBD192 was injected at $100 \mathrm{mg} / \mathrm{kg}$ on day 5 led to a marked decrease in the clinical score at day 6 (Figure 9C).

Taken together, the results obtained with the three mouse models of autoimmune disease suggested that LFBD192 has 20 to 80 -fold greater potency than IVIg. Furthermore, LFBD192 efficacy was slightly higher than that of Fc-MST-HN, an Fc with mutations that allow only FcRn optimization in a preventive ITP model, as well as that of a trivalent Fc in a mouse model of K/ BxN-induced arthritis. In the CAIA mouse model, LFBD192 had similar efficacy to the Fc-trimer.

\section{DISCUSSION}

Two mechanisms of action associated with pathogenic autoantibody-antigen ICs can be targeted. They circulate antibody levels and block the inflammatory pathways through a mechanism that seems to involve FcyRs expressed on the surface of effector cells.

As the half-life of IgGs is dependent on FcRn, several molecules (mAbs and FcRn ligands) that target FcRn are currently under development, aiming to reduce the levels of circulating antibodies, including autoantibodies (3, 5). IVIg infusion has been shown to reduce antibody levels by $40 \%$ and may aid in reducing inflammation in chronic autoimmune conditions $(31,32)$. However, the mechanism of action of IVIg is not limited to reducing plasmatic antibody levels. The $F\left(a b^{\prime}\right) 2$ portion of IVIg has been suggested to be involved in its immunomodulatory function as it is responsible for the neutralization of cytokines and autoantibodies, the blockade of cell-cell interactions, and C3a and C5a scavenging (15, 22). Many studies in mice have shown that the Fc portion of IVIg (obtained by digestion) often represents the active component of IVIg via interaction with Fc receptors, such as in ITP and arthritis (K/ $\mathrm{BxN}$ arthritis models) (33-35). The main direct mechanisms of action of the Fc portion of IVIg include FcRn saturation, activating FcyR blockade, and the modulation of activating $v s$ inhibitory Fc $\gamma R$ expression $(15,22)$.

The dual targeting of both FcRn and FcyRs seems to be the most promising therapeutic approach. Although clinical data on Fc fragments are encouraging $(10,11)$, the development of Fc fragments purified from IVIg does not resolve the IVIg supply problem and is too costly for therapeutic use, and a recombinant Fc could be the solution. To greatly reduce the administered dose, several derived Fc fragments have been developed (9). Notably, multivalent Fc molecules bind avidly to all Fc receptors and confer efficacy at much lower doses than IVIg. Highly ordered Fc multimers (stradomer/GL-2045) were shown to have high efficacy in several animal autoimmune models of ITP, collagen-induced arthritis (CIA) (23), myasthenia gravis (36), and experimental 


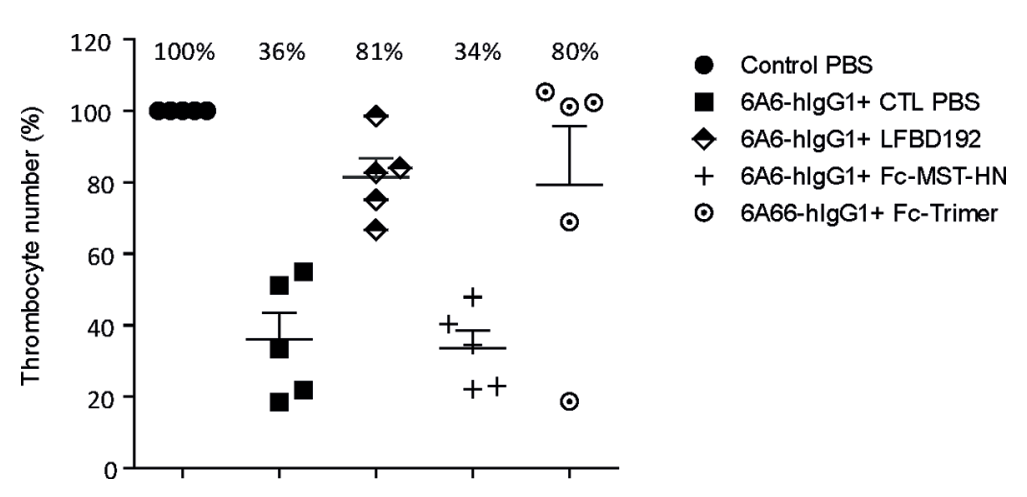

FIGURE 6 | LFBD192 displayed high potency in the prophylactic treatment of ITP in a humanized FcRn mouse model. Platelet numbers $24 \mathrm{~h}$ after intraperitoneal injection of anti-platelet 6A6-hlgG1 antibody and treatment with PBS, LFBD192, FC-MST-HN, and the Fc-trimer at $50 \mathrm{mg} / \mathrm{kg} 2 \mathrm{~h}$ before ITP induction. Data represent mean thrombocyte percentages \pm SEM $(N=5)$.

autoimmune neuritis (37). Smaller hexameric Fc constructs are also potent in CAIA, CIA, and ITP mouse models $(24,38)$. Nevertheless, the potential for Fc $\gamma \mathrm{R}$ cross-linking by multimeric $\mathrm{Fc}$ that could trigger immune cell activation and cytokine release similar to that seen with IgG aggregates is a safety consideration that should be addressed.

A multivalent Fc (GL-2045) did not induce statistically significant increases in the levels of any of the well-recognized pro-inflammatory cytokines in NHPs (39). Additionally, the injection of a hexameric Fc molecule in naïve animals elicited only limited cytokine release in mice and none in monkeys (24); however, in human blood safety assays, incubation with IgG1 isotype Fc hexamers resulted in cytokine release. Platelet and complement activation was avoided using Fc from IgG4 (40). Furthermore, trimeric $\mathrm{Fc}$ was determined to be the minimal structure to not activate immune effector cells (25). Specifically, pentameric $\mathrm{Fc}$ is a strong agonist of $\mathrm{Fc} \gamma \mathrm{R}$ and mediating in SYK and ERK phosphorylation.

Multivalent Fc (GL-2045) and trimeric Fc (CSL-730) safety evaluations are in progress in phase I clinical trials. However, to avoid potential Fc $\gamma \mathrm{R}$ cross-linking by multimeric Fc, we chose to develop a monovalent Fc, LFBD192, that was modified to have a binding profile similar to that of multivalent Fc.

We have shown that LFBD192 has a good in vitro safety profile regarding platelet and complement activation. Furthermore, in a human whole blood safety assay, incubation with LFBD192 did not result in cytokine release. This result contrasts with an IgG1 isotype hexavalent Fc safety concern in a similar test (40). The critical disparity between IgG1 and IgG4 isotype Fc hexamers related to cytokine release was suggested to be linked to their differential ability to bind FcyRs on neutrophils in whole blood, and particularly FcyRIIIb (40). We did not determine binding to FcyRIIIb; however, LFBD192 is bound to neutrophils with slightly lower affinity than that seen with the trivalent Fc. The in vitro safety profile of LFBD192 will need to be confirmed in a toxicology study in NHPs.

For the first time, a molecule was engineered that was significantly optimized for binding to the main Fc $\gamma$ Rs as well as FcRn. A recent review (41) described several mAbs with point mutations that enhance $\mathrm{Fc} \gamma \mathrm{R}$ binding to optimize the effector function of therapeutic mAbs or enhance FcRn binding to optimize the half-life of mAbs. Many examples have been reported where introducing a mutation in the $\mathrm{Fc}$ region can optimize the binding to one FcyR while also negatively influencing another (41). None of them has allowed the dual optimization of Fc $\gamma \mathrm{R}$ and FcRn binding as seen with LFBD192. Furthermore, our mutations have not been described elsewhere. The combination of the six mutations was unpredictable by rational design. The key mutations allowing optimization for FcRn binding were first identified through two successive rounds of random mutagenesis and phage display selection. This process allowed the exploration of a huge number of mutants $\left(1 \times 10^{7}\right.$ and $2 \times 10^{7}$, respectively) (26). Furthermore, two rounds of random mutagenesis/phage display selection relating to FcyRIIIa have allowed the identification of new key mutations that modulate the binding to FcrRIIIa (unpublished data). Data obtained from random mutagenesis were used to build a database of molecules designed by rational mutagenesis and binding properties related to the different FcyRs and FcRn (27). Here, we designed new mutants by combining mutations previously identified to optimize binding to $\mathrm{FcRn}$ with mutations that optimize binding to FcyRIIIa. Three steps of design/characterization led to the selection of the Y296W/K334N/P352S/A378V/V397M/ N434Y mutations in LFBD192. This molecule has a higher binding affinity than IVIg for the main human Fc $\gamma$ Rs and FcRn as well as for mouse FcRn and Fc $\gamma R I V$. Efgartigimod has recently shown efficacy in reducing serum IgG levels in humans (3) and elicited long-lasting disease improvement in myasthenia gravis patients (4). The mutations in efgartigimod (M252Y/ S254T/T256E/H433K/N434F) allowed the optimization of binding only to $\mathrm{FcRn}$ at both acidic $\left(K_{\mathrm{D}}: 14.2 \mathrm{nM}\right)$ and neutral $\mathrm{pH}\left(K_{\mathrm{D}}: 320 \mathrm{nM}\right)$ (3). In addition to being optimized for Fc $\gamma \mathrm{R}$ binding, LFBD192 also has a strong affinity for FcRn at $\mathrm{pH}$ 6.0, similar to efgartigimod. In contrast to efgartigimod, however, LFBD192 has no detectable binding at $\mathrm{pH} \mathrm{7.4,} \mathrm{allowing} \mathrm{the}$ conservation of the $\mathrm{pH}$ dependence. In a human clinical trial, efgartigimod has shown efficacy at the dose of $10 \mathrm{mg} / \mathrm{kg}$ administered four times over 3 weeks (4). Here, we compared 
A

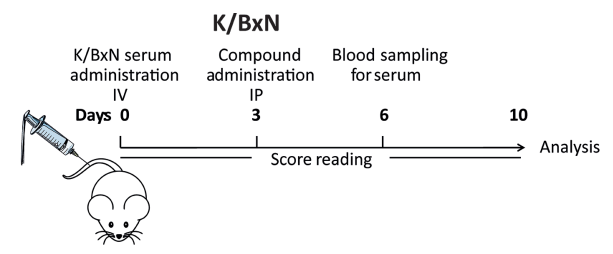

B

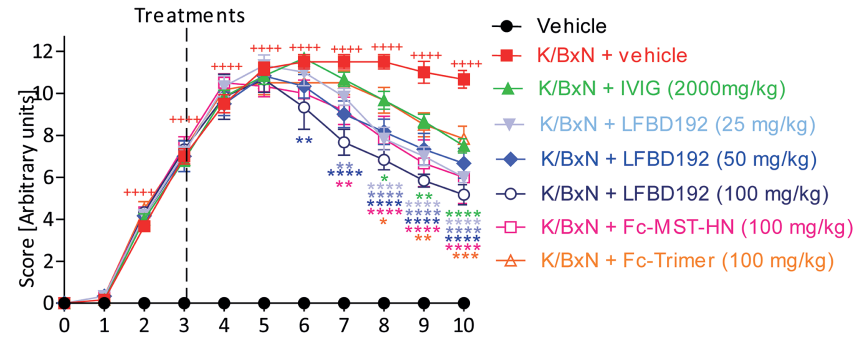

C

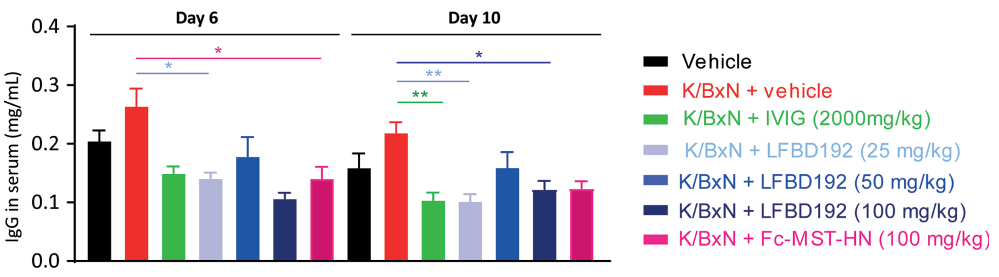

D

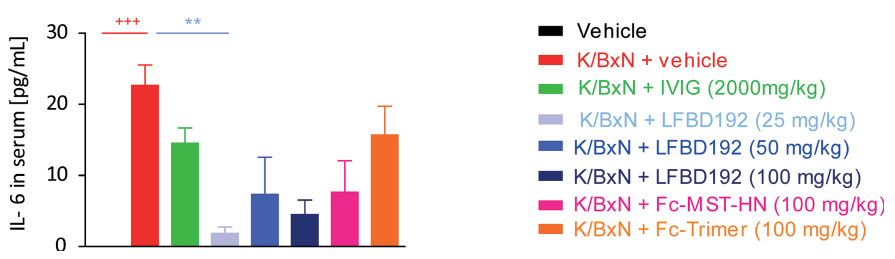

FIGURE 7 | LFBD192 ameliorated disease activity in a K/BXN-induced mouse model of acute arthritis. (A) Schematic representation of the mouse K/BxN model with administration of the compound 3 days after K/BxN serum injection. (B) Clinical scores after treatment with PBS, IVlg (2,000 mg/kg), LFBD192 (25, 50, and 100 $\mathrm{mg} / \mathrm{kg}$ ), Fc-MST-HN (100 mg/kg), and the Fc-trimer (100 mg/kg). (C) Serum lgG levels were reduced at days 6 and 10 in LFBD192-treated mice compared with mice treated with PBS. Bars represent mean serum lgG levels \pm SEM ( $N=6$ mice per group). This result is representative of at least two experiments. (D) The levels of systemic IL-6 were reduced at day 6 in LFBD192-treated mice. Bars represent mean serum IL-6 levels \pm SEM (N=6 mice per group). This result is representative of at least two experiments. Statistical evaluation of the differences among experimental groups was performed by two-way ANOVA followed by Dunnett's post-test. $P$-values $<0.05$ were considered significant. ${ }^{+++} p<0.001,{ }^{++++} p<0.0001$ : vehicle vs $\mathrm{K} / \mathrm{BXN}+$ vehicle; ${ }^{*} p<0.05,{ }^{* \star} p<0.01,{ }^{* \star *} p<0.001,{ }^{*{ }^{* * *}} p<0.0001$ : compared with $\mathrm{K}$ BxN + vehicle. All statistical analyses were performed using GraphPad Prism, version 8 for Windows (GraphPad Software Inc., San Diego, CA, USA).

LFBD192 to Fc-MST-HN, an Fc fragment produced in-house that contained the same mutations as efgartigimod. LFBD192 and Fc-MST-HN showed similar binding potential for FcRn (IC50 of 15 and $14 \mathrm{nM}$, respectively); however, Fc-MST-HN displayed a low affinity for Fc $\gamma$ RIIa, Fc $\gamma$ RIIIa, and Fc $\gamma$ RI (data not shown). Fc-MST-HN was not effective in the preventive ITP model at $50 \mathrm{mg} / \mathrm{kg}$, likely because determining platelet counts up to $24 \mathrm{~h}$ is not long enough to allow the anti-FcRn drug to substantially affect IgG elimination. Notably, in the ITP model, FcRn involvement was studied in the context of human FcRn (humanized FcRn mice and chimeric IgG1 anti-platelet antibody) and mouse Fc $\gamma$ Rs. Fc $\gamma$ RIV being the receptor mainly involved in the ITP mouse model induced through a human IgG1 Fc (6A6-hIgG1), the LFBD192 efficacy vs Fc-MST-HN could be explained with a higher binding and then inhibitory of
Fc $\gamma$ RIV dependent cytotoxicity mechanisms. In the arthritis model, the therapeutic administration of $100 \mathrm{mg} / \mathrm{kg}$ of FcMST-HN had similar potency to $25 \mathrm{mg} / \mathrm{kg}$ LFBD192. In addition, similar to that seen with Fc-MST-HN, LFBD192 could significantly reduce the levels of endogenous IgGs for at least 7 days after drug injection. An MST-HN variant in the IgG format was reported to elicit a similar reduction in circulating IgG in arthritic mice (3). In humans, we could expect to have a similar effect on IgG depletion at the efgartigimod doses with an additional effect on the acute inflammation targeting Fc $\gamma$ Rs. Although the efficacies of the molecules were assessed in the context of mouse Fc receptors, the increased binding affinity of LFBD192 compared with IVIg for mouse FcRn was shown to be proportionally similar for human FcRn. The higher inflammatory reduction of LFBD192 compared to Fc-MST-HN 
A

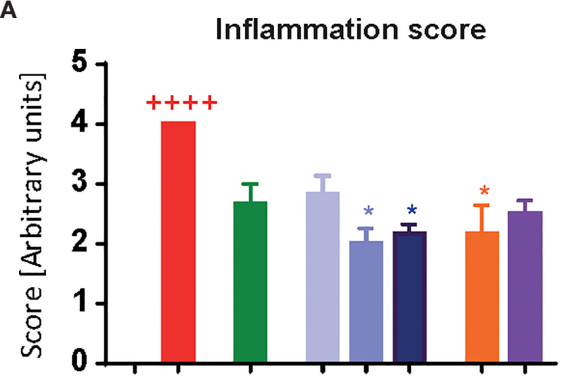

C

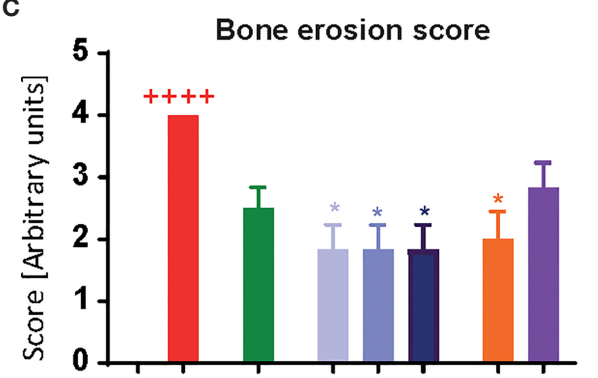

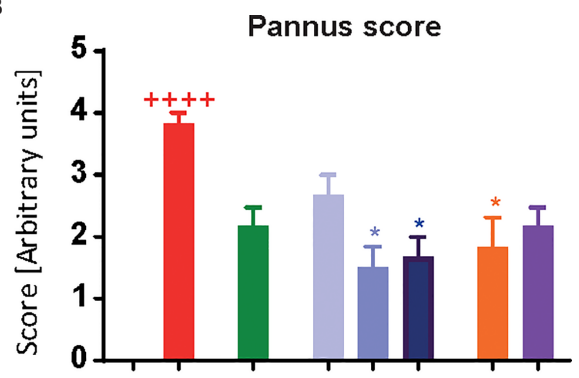

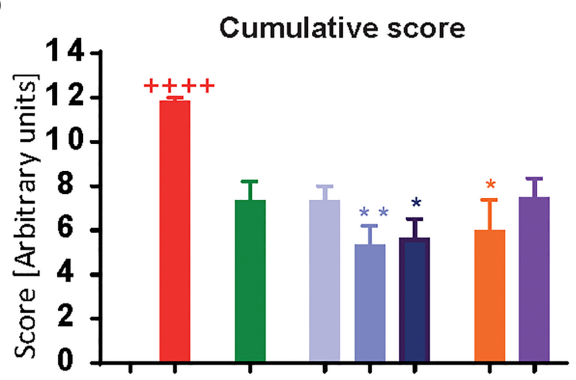

FIGURE 8 | LFBD192 ameliorates histological scores in a K/BxN mouse model. Effect of compounds IVlg (2000mg/kg), LFBD192 (25, 50 and 100mg/kg), FC-MST$\mathrm{HN}(100 \mathrm{mg} / \mathrm{kg})$ and Fc-trimer (100mg/kg) on histological scores. On day 10, mice were killed, and ankle joints were harvested and fixed in 10\% paraformaldehyde and decalcified for 10 days. Paraffin embedded sections were stained with hematoxylin \& eosin (H\&E) and scanned under a microscope. Histologic scoring including inflammation (A), bone erosion (B), pannus (C), and cumulative scores (D) are shown. The sections were graded using various parameters, as follows: severity of synovial hyperplasia (pannus formation), cellular exudates (inflammation), and cartilage depletion/bone erosion, each scored 0 [normal] to 5 [severe], and extent of synovial infiltrate, scored 0-5, with higher scores indicating greater infiltration. The grades for all parameters were subsequently summed to obtain the cumulative score. Quantitative data show mean and SEM from six animals per group from three independent experiments. Statistical analysis: Non parametric Kruskal-Wallis test followed by a Dunn's multiple comparisons test ${ }^{++++} p<0.0001$, Vehicle compared with $\mathrm{K} / \mathrm{BxN}+\mathrm{Vehicle;}{ }^{*} p<0.05,{ }^{\star \star} p<0.01, \mathrm{~K} / \mathrm{BxN}+\mathrm{Vehicle}$ compared with treatments.

seems to be due to an inhibitory effect of pathogenic IgG2a through a higher affinity for Fc $\gamma$ RIV.

An alternative anti-inflammatory mechanism was described using sialylated antibodies $(29,42,43)$. LFBD192 produced in $\mathrm{CHO}$ cells is not sialylated, suggesting a different mechanism of action mainly focused on the blockade of type I Fc $\gamma$ Rs and FcRn.

LFBD192 was also compared with a trivalent molecule (Fctrimer) designed and produced in-house based on the Fc3Y molecule described by Ortiz et al. (25). Fc3Y is currently undergoing a phase I clinical trial under the name CSL730. LFBD192 and the Fc-trimer were shown to have similar efficacy in the preventive ITP model. Fc3Y was reported to be very efficient in the CAIA model (25) and although LFBD192 and Fc-trimer were not compared simultaneously in the same experiment, we obtained comparable efficacy with the Fc-trimer at $100 \mathrm{mg} / \mathrm{kg}$ in our CAIA experiment. The slightly lower potency of the Fc-trimer at $100 \mathrm{mg} /$ $\mathrm{kg}$ in the $\mathrm{K} / \mathrm{BxN}$-induced mouse model of acute arthritis was surprising. The Fc-trimer and IVIg at 2,000 mg/kg showed similar clinical score evolutions and reductions in IL-6 levels. One explanation could be that a correlation exists between the size (50 $\mathrm{kDa}$ for monovalent Fc-fragments [LFBD192 and Fc-MST-HN] and $150 \mathrm{kDa}$ for IVIg and the Fc-trimer) and potency of the molecules that could allow better infiltration of the smaller molecules into the inflamed joints.

The risk of immunogenicity due to mutations introduced in a highly conserved human IgG1 Fc sequence could not be 
A

CAIA

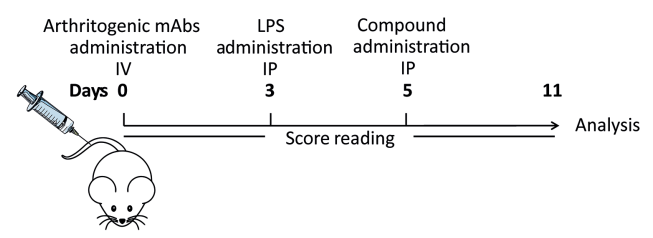

B

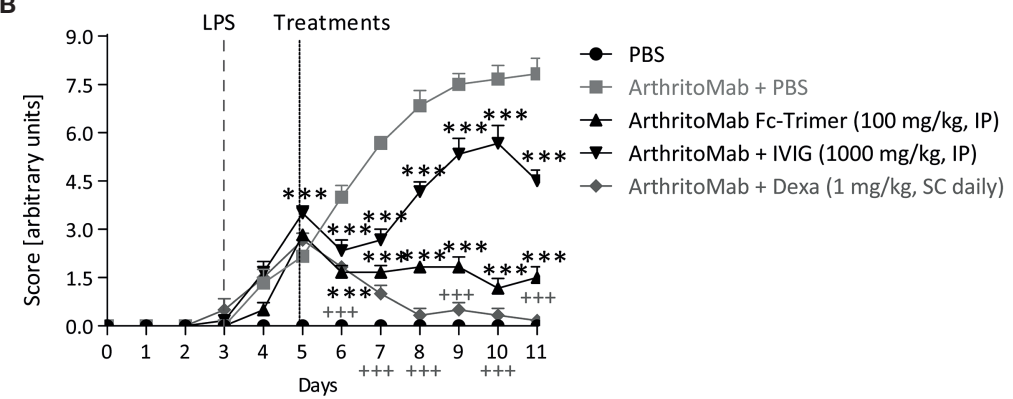

C

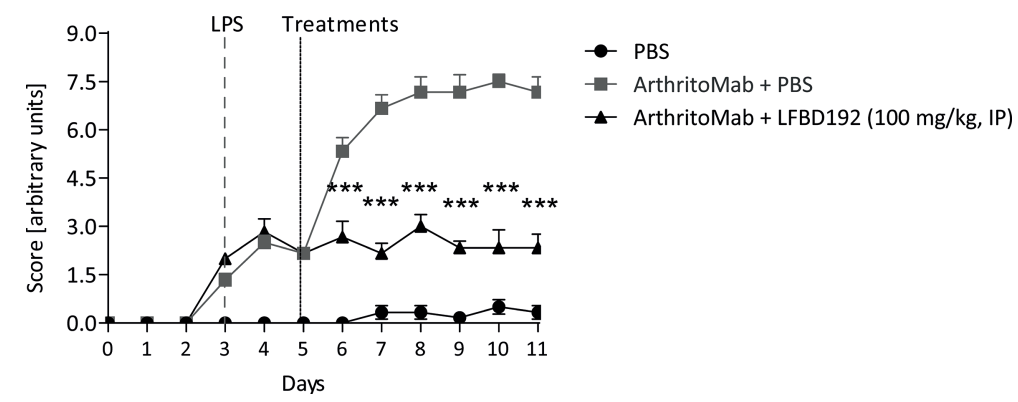

FIGURE 9 | LFBD192 displayed high potency in a mouse model of collagen antibody-induced arthritis (CAIA). (A) Schematic representation of the mouse model of CAIA with administration of the compound 5 days after anti-collagen antibody injection. (B) Clinical scores after treatment with PBS, the Fc-trimer (100 mg/kg), IVlg $(1,000 \mathrm{mg} / \mathrm{kg})$, and dexamethasone (1 mg/kg, daily). (C) Clinical scores after treatment with PBS and LFBD192 at $100 \mathrm{mg} / \mathrm{kg}$. Data represent the means \pm SEM of 6 mice per group. Statistical evaluation of the differences among the experimental groups was performed using two-way ANOVA followed by Bonferroni's post-test. $P$-values $<0.05$ were considered significant. ${ }^{+++} p<0.001$, Vehicle compared with CAIA + Vehicle; ${ }^{*} p<0.05,{ }^{* *} p<0.01,{ }^{* \star *} p<0.001,{ }^{* \star *} p<0.0001$ : compared with CAIA + vehicle. All the statistical analyses were performed using GraphPad Prism version 8 for Windows (GraphPad Software Inc.).

excluded. In humans, different modified Fc on mAbs, and, to our knowledge, Fc fusion proteins, have been administered without any reported immunogenicity. The injection of efgartigimod in human volunteers did not trigger the development of anti-drug $\mathrm{Ab}$ signals (3). The in-silico analysis undertaken by Lonza predicted that our 6 mutations presented only a low risk of immunogenicity. The DRB1 scores for LFBD192 were at the lower end of human marketed antibodies (data not shown).

The conservation of the $\mathrm{pH}$ dependence of LFBD192 allowed for the hypothesis that the mechanism of action underlying the effects of LFBD192 on FcyRs involves two steps: LFBD192 first blocks Fc $\gamma$ Rs on the surface of effector cells at physiological $\mathrm{pH}$ 7.4 , providing a rapid modulation of inflammation in the acute phase of the disease without being depleted via the binding to FcRn expressed on the surface of immune effector cells (monocytes, neutrophils, dendritic cells) and the endothelium. In a second step, LFBD192 saturates FcRn into the endosomal compartment at $\mathrm{pH} 6.0$ and then induces the clearance of plasmatic antibodies, including pathogenic autoantibodies. Combined, these results indicate that LFBD192 represents an innovative recombinant molecule with potential for application in the treatment of IgG-dependent autoimmune pathologies.

\section{DATA AVAILABILITY STATEMENT}

The original contributions presented in the study are included in the article/supplementary material. Further inquiries can be directed to the corresponding author. 


\section{ETHICS STATEMENT}

All CAIA experiments were associated with the Project No. 17_045 submitted to the Ethics Committee in Animal Experimentation (EAEC) No. 44 and approved by "le ministère de l'éducation nationale, de l'enseignement supérieur et de la recherche" under the number APAFIS \# 9410201703271734338. All K/BxN experiments were conducted in Artimmune laboratory (Orléans, France) and performed in compliance with the guidelines of the Agriculture French Ministry for experiments with laboratory animals (law 87-848). All animal experiments were approved by the "Ethics Committee for Animal Experimentation of CNRS Campus Orleans" (CCO) under number CLE CCO 2015-1081.

\section{AUTHOR CONTRIBUTIONS}

CM designed the mutants and analyzed the data. AB and AT produced the variants in HEK cells and characterized them. EJ wrote and revised the manuscript, designed and analyzed all the in vivo experiments, and performed the in vivo CAIA experiments. GD, DD, and $\mathrm{AE}$ performed some of the in vitro experiments. CRo and NF designed and analyzed some of the in vitro experiments. $\mathrm{CB}$ and $\mathrm{AL}$ performed production, purification of LFBD192 at a larger scale, and characterizations. AF performed the in-silico immunogenicity study and with TA, designed and analyzed production, purification at a larger scale of LFBD192 and revised the manuscript. AS performed and analyzed the Biacore experiments. LD, MN, and NM designed and performed LFBD192 $\mathrm{CHO}$ production and purification. $\mathrm{AR}$ and FD designed and performed the experiment involving the inhibition of antibodymediated platelet phagocytosis. DT and LF designed and

\section{REFERENCES}

1. Ludwig RJ, Vanhoorelbeke K, Leypoldt F, Kaya Z, Bieber K, McLachlan SM, et al. Mechanisms of Autoantibody-Induced Pathology. Front Immunol (2017) 8:603. doi: 10.3389/fimmu.2017.00603

2. Patel DA, Puig-Canto A, Challa DK, Perez Montoyo H, Ober RJ, Ward ES. Neonatal Fc Receptor Blockade by Fc Engineering Ameliorates Arthritis in a Murine Model. J Immunol (2011) 187:1015-22. doi: 10.4049/jimmunol. 1003780

3. Ulrichts P, Guglietta A, Dreier T, van Bragt T, Hanssens V, Hofman E, et al. Neonatal Fc Receptor Antagonist Efgartigimod Safely and Sustainably Reduces Iggs in Humans. J Clin Invest (2018) 128:4372-86. doi: 10.1172/ JCI97911

4. Howard JF, Bril V, Burns TM, Mantegazza R, Bilinska M, Szczudlik A, et al. Randomized Phase 2 Study of Fcrn Antagonist Efgartigimod in Generalized Myasthenia Gravis. Neurology (2019) 92:e2661-73. doi: 10.1212/WNL. 0000000000007600

5. Kiessling P, Lledo-Garcia R, Watanabe S, Langdon G, Tran D, Bari M, et al. The Fcrn Inhibitor Rozanolixizumab Reduces Human Serum Igg Concentration: A Randomized Phase 1 Study. Sci Transl Med (2017) 9 (414):eaan1208. doi: 10.1126/scitranslmed.aan1208

6. Ling LE, Hillson JL, Tiessen RG, Bosje T, van Iersel MP, Nix DJ, et al. M281, an Anti-Fcrn Antibody: Pharmacodynamics, Pharmacokinetics, and Safety Across the Full Range of Igg Reduction in a First-in-Human Study. Clin Pharmacol Ther (2018) 105:1031-9. doi: 10.1002/cpt.1276

7. Robak T, Kaźmierczak M, Jarque I, Musteata V, Treliński J, Cooper N, et al. Phase 2 Multiple-Dose Study of an Fcrn Inhibitor, Rozanolixizumab, in performed the $\mathrm{K} / \mathrm{BxN}$-related in vivo experiments. IS and $\mathrm{FN}$ designed and performed the in vivo ITP-related experiments. WS and SC designed the research and revised the manuscript. PM wrote the manuscript, designed and analyzed all the in vivo experiments, designed the research, and analyzed the data. All authors contributed to the article and approved the submitted version.

\section{FUNDING}

The authors declare that this study received funding from LFB Biotechnologies, Les Ulis, France. The funder was not involved in the study design, collection, analysis, interpretation of data, the writing of this article or the decision to submit it for publication. $\mathrm{FN}$ is supported by grants from the German Research foundation (DFG-FOR2886 and CRC1181-A07).

\section{ACKNOWLEDGMENTS}

We thank Marie Berger, Manon Bastin-Heline, and Arthur Besle for the SPR analysis; Bianca Boussier and Sylvie Le Ver for technical help and expertise with the in vivo experiments; Virginie Pochet-Beghin and Anne-Sophie Dezetter for technical help in purification and characterization; Lucie Verhaeghe for technical help with in vitro characterization; Philippe Klein and Abdel Zemmar from LFB Biomanufacturing for technical help with stable clone generation. We are also grateful to Herve Friedman, Harry Meade, and Lihow Chen for their scientific expertise and advice.

Patients With Primary Immune Thrombocytopenia. Blood Adv (2020) 4:4136-46. doi: 10.1182/bloodadvances.2020002003

8. Bayry J, Kaveri SV. Kill 'Em All: Efgartigimod Immunotherapy for Autoimmune Diseases. Trends Pharmacol Sci (2018) 39:919-22. doi: 10.1016/j.tips.2018.08.004

9. Zuercher AW, Spirig R, Baz Morelli A, Rowe T, Käsermann F. NextGeneration Fc Receptor-Targeting Biologics for Autoimmune Diseases. Autoimmun Rev (2019) 18:102366. doi: 10.1016/j.autrev.2019.102366

10. Debré M, Bonnet MC, Fridman WH, Carosella E, Philippe N, Reinert P, et al. Infusion of FC Gamma Fragments for Treatment of Children With Acute Immune Thrombocytopenic Purpura. Lancet (1993) 342:945-9. doi: 10.1016/ 0140-6736(93)92000-j

11. Hsu CH, Chen MR, Hwang FY, Kao HA, Hung HY. Efficacy of Plasmin-Treated Intravenous Gamma-Globulin for Therapy of Kawasaki Syndrome. Pediatr Infect Dis J (1993) 12:509-12. doi: 10.1097/00006454-199306000-00010

12. Podolanczuk A, Lazarus AH, Crow AR, Grossbard E, Bussel JB. Of Mice and Men: An Open-Label Pilot Study for Treatment of Immune Thrombocytopenic Purpura by an Inhibitor of Syk. Blood (2009) 113:315460. doi: 10.1182/blood-2008-07-166439

13. Bussel JB, Arnold DM, Boxer MA, Cooper N, Mayer J, Zayed H, et al. LongTerm Fostamatinib Treatment of Adults With Immune Thrombocytopenia During the Phase 3 Clinical Trial Program. Am J Hematol (2019) 94:546-53. doi: 10.1002/ajh.25444

14. Li X, Gibson AW, Kimberly RP. Human Fcr Polymorphism and Disease. Curr Top Microbiol Immunol (2014) 382:275-302. doi: 10.1007/978-3-319-07911-0_13

15. Schwab I, Nimmerjahn F. Intravenous Immunoglobulin Therapy: How Does Igg Modulate the Immune System? Nat Rev Immunol (2013) 13:176-89. doi: $10.1038 /$ nri3401 
16. Fleit HB, Wright SD, Unkeless JC. Human Neutrophil Fc Gamma Receptor Distribution and Structure. Proc Natl Acad Sci USA (1982) 79:3275-9. doi: 10.1073/pnas.79.10.3275

17. Clarkson SB, Bussel JB, Kimberly RP, Valinsky JE, Nachman RL, Unkeless JC. Treatment of Refractory Immune Thrombocytopenic Purpura With an Anti-Fc Gamma-Receptor Antibody. N Engl J Med (1986) 314:1236-9. doi: 10.1056/ NEJM198605083141907

18. Bussel JB. Fc Receptor Blockade and Immune Thrombocytopenic Purpura. Semin Hematol (2000) 37:261-6. doi: 10.1016/s0037-1963(00)90104-5

19. Psaila B, Bussel JB. Fc Receptors in Immune Thrombocytopenias: A Target for Immunomodulation? J Clin Invest (2008) 118:2677-81. doi: 10.1172/JCI36451

20. Yu X, Lazarus AH. Targeting Fc $\gamma$ rs to Treat Antibody-Dependent Autoimmunity. Autoimmun Rev (2016) 15:510-2. doi: 10.1016/ j.autrev.2016.02.006

21. Norris PA, Segel GB, Burack WR, Sachs UJ, Lissenberg-Thunnissen SN, Vidarsson G, et al. Fc $\gamma$ ri and Fc $\gamma$ riii on Splenic Macrophages Mediate Phagocytosis of Anti-Glycoprotein Iib/Iiia Autoantibody-Opsonized Platelets in Immune Thrombocytopenia. Haematologica (2021) 106:250-4. doi: 10.3324/haematol.2020.248385

22. Lünemann JD, Nimmerjahn F, Dalakas MC. Intravenous Immunoglobulin in Neurology-Mode of Action and Clinical Efficacy. Nat Rev Neurol (2015) 11:80-9. doi: 10.1038/nrneurol.2014.253

23. Jain A, Olsen HS, Vyzasatya R, Burch E, Sakoda Y, Mérigeon EY, et al. Fully Recombinant Igg2a Fc Multimers (Stradomers) Effectively Treat CollagenInduced Arthritis and Prevent Idiopathic Thrombocytopenic Purpura in Mice. Arthritis Res Ther (2012) 14:R192. doi: 10.1186/ar4024

24. Qureshi OS, Rowley TF, Junker F, Peters SJ, Crilly S, Compson J, et al. Multivalent $\mathrm{Fc} \gamma$-Receptor Engagement by a Hexameric Fc-Fusion Protein Triggers $\mathrm{Fc} \gamma$-Receptor Internalisation and Modulation of Fc $\gamma$-Receptor Functions. Sci Rep (2017) 7:17049. doi: 10.1038/s41598-017-17255-8

25. Ortiz DF, Lansing JC, Rutitzky L, Kurtagic E, Prod'homme T, Choudhury A, et al. Elucidating the Interplay Between Igg-Fc Valency and Fc $\gamma$ r Activation for the Design of Immune Complex Inhibitors. Sci Transl Med (2016) 8:365ra158. doi: 10.1126/scitranslmed.aaf 9418

26. Monnet C, Jorieux S, Souyris N, Zaki O, Jacquet A, Fournier N, et al. Combined Glyco- and Protein-Fc Engineering Simultaneously Enhance Cytotoxicity and Half-Life of a Therapeutic Antibody. MAbs (2014) 6:42236. doi: $10.4161 /$ mabs. 27854

27. Monnet C, Jorieux S, Urbain R, Fournier N, Bouayadi K, de Romeuf C, et al. Selection of Igg Variants With Increased Fcrn Binding Using Random and Directed Mutagenesis: Impact on Effector Functions. Front Immunol (2015) 6:39. doi: 10.3389/fimmu.2015.00039

28. Anthony RM, Kobayashi T, Wermeling F, Ravetch JV. Intravenous Gammaglobulin Suppresses Inflammation Through a Novel $\mathrm{T}(\mathrm{H}) 2$ Pathway. Nature (2011) 475:110-3. doi: 10.1038/nature10134

29. Bas M, Terrier A, Jacque E, Dehenne A, Pochet-Béghin V, Beghin C, et al. Fc Sialylation Prolongs Serum Half-Life of Therapeutic Antibodies. J Immunol (2019) 202:1582-94. doi: 10.4049/jimmunol.1800896

30. Bruhns P, Samuelsson A, Pollard JW, Ravetch JV. Colony-Stimulating Factor1-Dependent Macrophages Are Responsible for IVIG Protection in AntibodyInduced Autoimmune Disease. Immunity (2003) 18:573-81. doi: 10.1016/ s1074-7613(03)00080-3

31. Hansen RJ, Balthasar JP. Intravenous Immunoglobulin Mediates an Increase in Anti-Platelet Antibody Clearance via the Fcrn Receptor. Thromb Haemost (2002) 88:898-9. doi: 10.1055/s-0037-1613331

32. Li N, Zhao M, Hilario-Vargas J, Prisayanh P, Warren S, Diaz LA, et al. Complete Fcrn Dependence for Intravenous Ig Therapy in Autoimmune Skin Blistering Diseases. J Clin Invest (2005) 115:3440-50. doi: 10.1172/JCI24394

33. Anthony RM, Nimmerjahn F, Ashline DJ, Reinhold VN, Paulson JC, Ravetch JV. Recapitulation of IVIG Anti-Inflammatory Activity With a Recombinant Igg Fc. Science (2008) 320:373-6. doi: 10.1126/science.1154315
34. Campbell IK, Miescher S, Branch DR, Mott PJ, Lazarus AH, Han D, et al. Therapeutic Effect of IVIG on Inflammatory Arthritis in Mice Is Dependent on the Fc Portion and Independent of Sialylation or Basophils. J Immunol (2014) 192:5031-8. doi: 10.4049/jimmunol.1301611

35. Samuelsson A, Towers TL, Ravetch JV. Anti-Inflammatory Activity of IVIG Mediated Through the Inhibitory Fc Receptor. Science (2001) 291:484-6. doi: 10.1126/science.291.5503.484

36. Thiruppathi M, Sheng JR, Li L, Prabhakar BS, Meriggioli MN. Recombinant Igg2a Fc (M045) Multimers Effectively Suppress Experimental Autoimmune Myasthenia Gravis. J Autoimmun (2014) 52:64-73. doi: 10.1016/ j.jaut.2013.12.014

37. Niknami M, Wang M-X, Nguyen T, Pollard JD. Beneficial Effect of a Multimerized Immunoglobulin $\mathrm{Fc}_{\mathrm{C}}$ in an Animal Model of Inflammatory Neuropathy (Experimental Autoimmune Neuritis). J Peripher Nerv Syst (2013) 18:141-52. doi: 10.1111/jns5.12022

38. Spirig R, Campbell IK, Koernig S, Chen C-G, Lewis BJ, Butcher R, et al. Rigg1 Fc Hexamer Inhibits Antibody-Mediated Autoimmune Disease via Effects on Complement and Fcrrs. J Immunol (2018) 200:2542-53. doi: 10.4049/ jimmunol.1701171

39. Zhang X, Owens J, Olsen HS, So E, Burch E, McCroskey MC, et al. A Recombinant Human Igg1 Fc Multimer Designed to Mimic the Active Fraction of IVIG in Autoimmunity. JCI Insight (2019) 4(2):e121905. doi: 10.1172/jci.insight.121905

40. Rowley TF, Peters SJ, Aylott M, Griffin R, Davies NL, Healy LJ, et al. Engineered Hexavalent Fc Proteins With Enhanced Fc-Gamma Receptor Avidity Provide Insights Into Immune-Complex Interactions. Commun Biol (2018) 1:146. doi: 10.1038/s42003-018-0149-9

41. Saunders KO. Conceptual Approaches to Modulating Antibody Effector Functions and Circulation Half-Life. Front Immunol (2019) 10:1296. doi: 10.3389/fimmu.2019.01296

42. Kaneko Y, Nimmerjahn F, Ravetch JV. Anti-Inflammatory Activity of Immunoglobulin G Resulting From Fc Sialylation. Science (2006) 313:6703. doi: $10.1126 /$ science. 1129594

43. Washburn N, Schwab I, Ortiz D, Bhatnagar N, Lansing JC, Medeiros A, et al. Controlled Tetra-Fc Sialylation of Ivig Results in a Drug Candidate With Consistent Enhanced Anti-Inflammatory Activity. Proc Natl Acad Sci USA (2015) 112:E1297-306. doi: 10.1073/pnas.1422481112

Conflict of Interest: Authors CM, EJ, CRe, AF, TA, NF, GD, DD, AE, AB, AT, AS, $\mathrm{CB}, \mathrm{AL}, \mathrm{NM}, \mathrm{LD}, \mathrm{MN}, \mathrm{AR}, \mathrm{FD}, \mathrm{WS}, \mathrm{SC}$ and $\mathrm{PM}$ are employees of LFB Biotechnologies, which patented the described Fc mutations. DT and LF are employees of Artimmune.

The remaining authors declare that the research was conducted in the absence of any commercial or financial relationships that could be construed as a potential conflict of interest.

Publisher's Note: All claims expressed in this article are solely those of the authors and do not necessarily represent those of their affiliated organizations, or those of the publisher, the editors and the reviewers. Any product that may be evaluated in this article, or claim that may be made by its manufacturer, is not guaranteed or endorsed by the publisher.

Copyright $\odot 2021$ Monnet, Jacque, de Romeuf, Fontayne, Abache, Fournier, Dupont, Derache, Engrand, Bauduin, Terrier, Seifert, Beghin, Longue, Masiello, Danino, Nogre, Raia, Dhainaut, Fauconnier, Togbe, Reitinger, Nimmerjahn, Stevens, Chtourou and Mondon. This is an open-access article distributed under the terms of the Creative Commons Attribution License (CC BY). The use, distribution or reproduction in other forums is permitted, provided the original author(s) and the copyright owner(s) are credited and that the original publication in this journal is cited, in accordance with accepted academic practice. No use, distribution or reproduction is permitted which does not comply with these terms. 